\title{
A Produção de Conhecimento sobre Violão em Dois Eventos
} Nacionais (2007-2018)

\author{
Jonathan Douglas Lopo Martins e Renan Colombo Simóes \\ Universidade do Estado do Rio Grande do Norte | Brasil
}

\begin{abstract}
Resumo: A presente pesquisa tem, como objetivo principal, a realização de um mapeamento dos trabalhos que abordam o violão nos anais do Simpósio Acadêmico de Violão da Escola de Música e Belas Artes do Paraná (EMBAP) e do Congresso da Associação Brasileira de Performance Musical (ABRAPEM). A metodologia utilizada foi a pesquisa bibliográfica, fundamentada por Ângelo Domingos Salvador, Eva Maria Lakatos e Marina de Andrade Marconi e Antonio Carlos Gil. A coleta de dados consistiu na identificação dos artigos que focalizam o violão, através da leitura do título, palavras-chave, resumo e, quando necessário, das considerações finais e corpo do texto. Os 148 trabalhos identificados foram organizados em sete grandes categorias: Análise, Estudo violonístico, Escrita violonística, Pedagogia do violão, Aspectos biográficos e históricos do violão brasileiro, Técnica e Outros.
\end{abstract}

Palavras-chave: Violão, Produção de conhecimento, Estado da arte, Simpósio Acadêmico da Escola de Música e Belas Artes do Paraná (EMBAP), Associação Brasileira de Performance Musical (ABRAPEM).

\begin{abstract}
The present research aims to map the articles that approach the guitar in the annals of the Academic Guitar Symposium of the Escola de Música e Belas Artes do Paraná (EMBAP) and the Congress of Associação Brasileira de Performance Musical (ABRAPEM). The methodology used was the bibliographic research, based on Ângelo Domingos Salvador, Eva Maria Lakatos and Marina de Andrade Marconi, and Antonio Carlos Gil. Data collection consisted of identifying the articles that focus on the guitar, by reading the title, keywords, summary and, when necessary, the final considerations and the text itself. The 148 identified works were organized in seven major categories: Analysis, Guitar study, Guitar writing, Guitar pedagogy, Biographical and historical aspects of the Brazilian guitar, Technique and Others.
\end{abstract}

Keywords: Guitar. Knowledge production, State of art, Academic Guitar Symposium of the Escola de Música e Belas Artes do Paraná (EMBAP), Associação Brasileira de Performance Musical (ABRAPEM). 


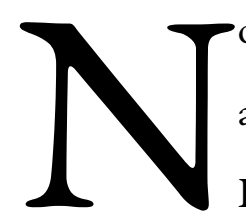

Brasil, a produção de conhecimento sobre violão tem se consolidado ao longo dos anos, através de trabalhos que se enquadram, majoritariamente, nas subáreas de Performance, Educação Musical e Composição. A quantidade de publicações e temáticas abordadas já justifica a realização de pesquisas bibliográficas sobre a produção acadêmica para o violão, como a realizada por Antunes (2012), que analisou teses e dissertaçóes defendidas em universidades brasileiras entre 1991 e 2007. Pesquisas de estado do conhecimento apresentam um olhar panorâmico sobre a produção existente e consistem em grandes contribuições para pesquisas futuras. Vosgerau; Romanowski (2014) apontam a importância de trabalhos dessa natureza, no tocante à compreensão de uma determinada área, por desvelar propensóes teórico-metodológicas, tendências, recorrências e lacunas.

Propomos, em nosso trabalho, a realização de um mapeamento dos trabalhos que abordam o violão nos anais do Simpósio Acadêmico de Violão da Escola de Música e Belas Artes do Paraná (EMBAP) e do Congresso da Associação Brasileira de Performance Musical (ABRAPEM), a partir da localização dos artigos que abordam essa temática e sua posterior análise e categorização. Os dois eventos foram escolhidos por sua regularidade, magnitude e relevância no cenário nacional. Este trabalho encontra-se fundamentado em três teóricos que discutem a pesquisa bibliográfica (SALVADOR, 1981; LAKATOS; MARCONI, 1992; GIL, 2002) e em autores que relatam o processo de pesquisa bibliográfica em Música.

\section{Pesquisa bibliográfica}

Sobre pesquisa bibliográfica, Gil (2002, p. 59) destaca que não se deve impor modelos, os quais devem ser entendidos, nesse tipo de pesquisa, de forma arbitrária. Segundo o autor:

A pesquisa bibliográfica, como qualquer outra modalidade de pesquisa, desenvolve-se ao longo de uma série de etapas. Seu número, assim como seu encadeamento, depende de muitos fatores, tais como a natureza do problema, o nível de conhecimento que o pesquisador dispóe sobre o assunto, o grau de precisão que se pretende conferir à pesquisa etc. (GIL, 2002, p. 59).

Dessa forma, Gil se remete à pesquisa bibliográfica como um procedimento de etapas sucessivas. Entre os autores consultados, há um consenso em relação à seguinte sistemática: escolha 
do tema, elaboração do plano de trabalho, identificação, localização, compilação, fichamento, análise e interpretação, e redação. Os autores discutem que, com o devido aprofundamento de cada etapa, este processo poderá proporcionar uma pesquisa bibliográfica muito bem fundamentada.

Para Lakatos; Marconi (1992, p. 43), esse tipo de pesquisa pode ser considerado como o primeiro passo de toda pesquisa científica, com a finalidade de colocar o pesquisador em contato direto com tudo aquilo que já foi publicado sobre determinado tema, permitindo uma análise das ideias e até a manipulação de suas informações.

As autoras destacam duas formas de fazer esse levantamento: (1) a coleta documental, que tem por finalidade fazer o levantamento dos dados no próprio local onde os fenômenos ocorreram; (2) as fontes de dados, na maioria das vezes, de outras pessoas. Assim, pesquisas dessa natureza dividem-se em pesquisas de fontes primárias, que são as documentais, e pesquisas de fontes secundárias, que se caracterizam como pesquisas bibliográficas.

Salvador (1981, p. 89-92) apresentou um olhar mais aprofundado e didático sobre as etapas de pesquisa, cuja finalidade é colocar o pesquisador em contato direto com o que foi escrito sobre determinado assunto, através da coleta em fontes diversas, como livros, revistas e publicaçóes online e impressas.

Além dos autores que discorrem especificamente sobre pesquisa bibliográfica, nos fundamentamos também em pesquisas bibliográficas realizadas em Música, o que nos auxiliou de forma prática na organização do trabalho (FERNANDES, 1999; FERNANDES, 2000; FERNANDES, 2006; ANTUNES, 2012; PIRES; DALBEN, 2013; SILVA, 2014; FANTINI; JOLY; ROSE, 2017; CIL; GONÇALVES, 2018; CANDEMIL, 2019).

Em Fernandes (1999; 2000; 2006), observamos uma pesquisa continuada, na qual o autor aborda a situação da pesquisa em Educação Musical a partir da análise de dissertaçóes e teses dos cursos de pós-graduação stricto sensu brasileiros. O primeiro trabalho (FERNANDES, 1999) foca em verificar quantitativamente a produção do conhecimento em Educação Musical, e realiza uma comparação entre as áreas de Educação e Educação Musical. O autor elaborou uma lista das publicações e utilizou, no corpo do trabalho, tabelas e gráficos para apontar as diferenças entre as publicações. Na segunda publicação (FERNANDES, 2000), o autor utiliza os mesmos dados da pesquisa anterior, aproveitando o título, resumo, gráficos, tabelas e listas, e inclui pontos de vista dos 
autores ao texto. Em suas consideraçóes, o autor aponta, dentre outras questóes, as categorias com menos publicações, e as regióes do país com mais publicações. $\mathrm{Na}$ terceira publicação (FERNANDES, 2006) rememora os dados coletados anteriormente, a partir de 1999, e os atualiza com as novas publicações. $\mathrm{O}$ autor utilizou, nos três trabalhos, o método estatístico/catalográfico, e apontou os seguintes resultados: o aumento de publicações, graças à ampliação dos cursos de pósgraduação; produções em outras áreas de conhecimento; categorias com menor índice de publicações.

Candemil (2019) realizou um levantamento de publicaçóes sobre o contexto musical do candomblé defendidas nos programas brasileiros de pós-graduação. O autor utilizou, para busca, o Portal de Periódicos CAPES, no qual identificou trabalhos sobre a temática em outras áreas além da Música, como Antropologia e Sociologia. Por fim, foi realizada uma análise crítica e comparativa entre o material coletado.

As tabelas e gráficos apresentados por Antunes (2012), Pires; Dalben (2013), Silva (2014), Fernandes (1999; 2000; 2006), Fantini; Joly; Rose (2017), Cil; Gonçalves (2018) e Candemil (2019) auxiliam o leitor na visualização panorâmica dos resultados, e serviram como base para a nossa apresentação final de dados. Observamos também, nesses autores, a abordagem quantitativa das publicações por ano, por região do país e por categoria. Optamos, em nossa pesquisa, por apresentar os dados por ano e por categoria; a apresentação por região do país não se aplica em nosso trabalho, por se tratar em um levantamento de dois eventos específicos, embora possamos realizar uma discussão sobre as instituiçôes de origem dos autores em publicação futura.

\subsection{Procedimento de coleta de dados}

O Simpósio Acadêmico de Violão da Escola de Música e Belas Artes do Paraná (EMBAP) é um evento específico de violão, e teve sua primeira edição em 2007. O Congresso da Associação Brasileira de Performance Musical (ABRAPEM) é dedicado à subárea de Performance Musical, e sua primeira edição ocorreu em 2013. Ambos eventos foram escolhidos por sua regularidade, magnitude e relevância no cenário nacional. A busca pelos trabalhos se deu nos sites da EMBAP e ABRAPEM, e em sites de busca; entretanto, nem todos os anais foram identificados.

A categorização dos artigos coletados deu-se através da leitura minuciosa dos títulos, palavras- 
chave, resumos e, quando necessário, considerações finais e corpo dos textos. O processo de definição das categorias deu-se, inicialmente, a partir de hipóteses sobre possíveis temáticas; entretanto, estas se consolidaram ao longo do processo. As categorias com mais de 10 trabalhos foram mantidas; quanto às demais, foram agrupadas em uma categoria com trabalhos diversos (Outros).

\section{Análise dos dados}

Durante a coleta de dados, identificamos um total de 12 eventos $^{1}$, divididos entre 8 simpósios da EMBAP e 4 congressos da ABRAPEM, totalizando 148 trabalhos que focalizaram o violão: 133 artigos nos Simpósios da EMBAP e outros 16 artigos nos congressos da ABRAPEM. Estes números são representados na tabela a seguir:

TABELA 1 - Artigos sobre violão identificados nos anais da ABRAPEM e EMBAP (2007-2018)

\begin{tabular}{lclc}
\hline Eventos (2007-2018) & & Artigos (2007-2018) & 132 \\
\hline Simpósios da EMBAP & 8 & Artigos EMBAP & 16 \\
Congressos da ABRAPEM & 4 & Artigos ABRAPEM & 148 \\
Total & 12 & Total & \\
\hline
\end{tabular}

Fonte: Autores

Vale ressaltar que a diferença numérica presente na tabela se justifica pelo fato do Congresso da ABRAPEM ser mais jovem e abordar a subárea de Performance Musical como um todo, diferente da EMBAP, que é específico de violão, e teve sua primeira edição em 2007. Diante desses dados, percebemos que existe uma vasta produção acadêmica sobre o violão nesses dois repositórios. $\mathrm{Na}$ Figura 1, podemos visualizar a quantidade de publicações em cada evento por ano:

\footnotetext{
${ }^{1}$ Não identificamos os anais do IV Simpósio Acadêmico de Violão da EMBAP, do III Congresso da ABRAPEM e do V Congresso da ABRAPEM.
} 


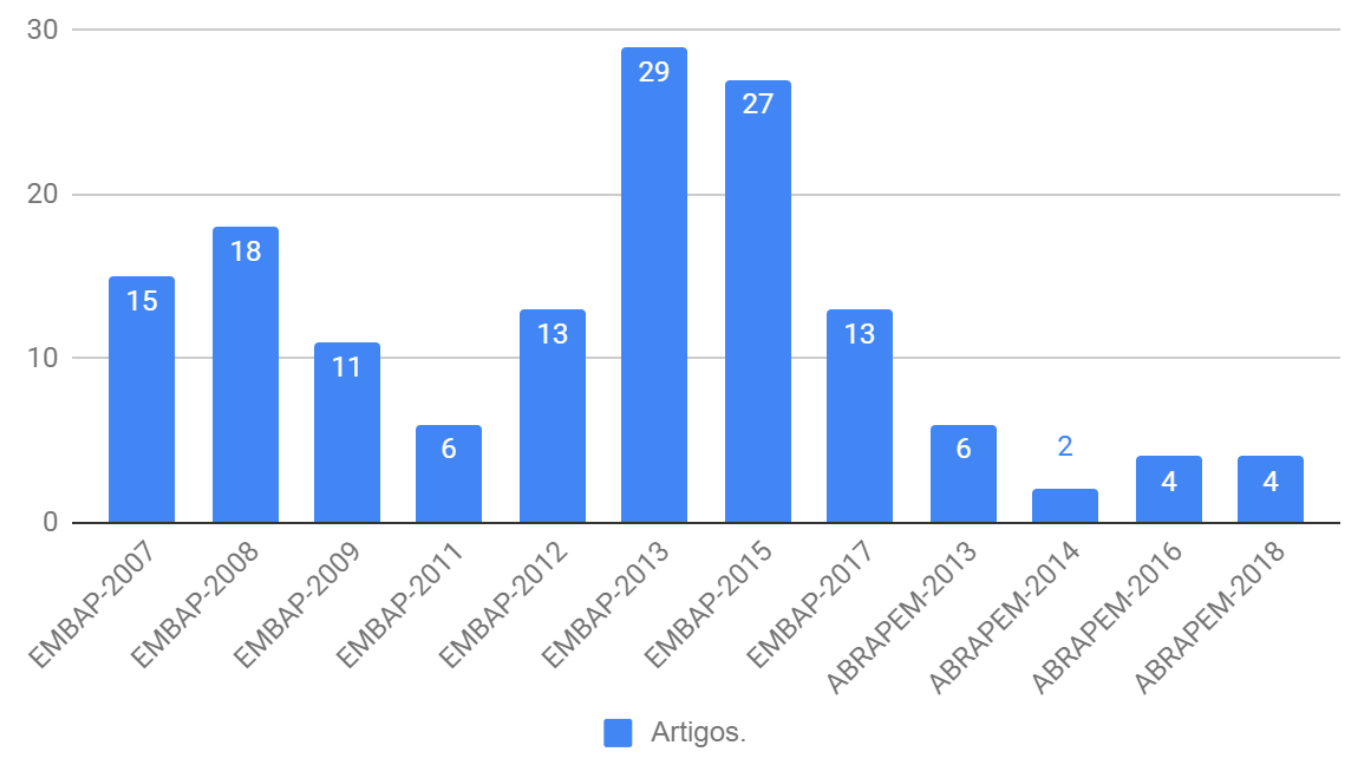

Fonte: Autores

O Congresso da ABRAPEM manteve uma média de 4 publicações sobre violão nos congressos consultados; no Simpósio da EMBAP, identificamos entre 11 e 19 publicações na maioria das edições, com um decréscimo de publicaçóes em 2011, e um aumento significativo nos eventos de 2013 e 2015.

Os artigos identificados foram enquadrados nas seguintes categorias: Análise, Estudo violonistico, Escrita violonistica, Pedagogia do violão, Aspectos biográficos e históricos do violão brasileiro, Técnica e Outros.

A categoria Análise compreende trabalhos que se fundamentaram metodologicamente em ferramentas analíticas diversas, como a análise schenkeriana, macro-análise, análise estética, análise do tempo musical, entre outras.

A categoria Estudo violonistico constitui-se de trabalhos sobre interpretação, leitura musical, leitura à primeira vista, preparação para performance, planejamento da performance, estratégias de estudos para violão, digitação, entre outros. Inicialmente, incluímos nessa categoria os trabalhos relacionados à técnica violonística, mas, devido ao grande quantitativo dessa temática específica, criamos a categoria Técnica. 
A categoria Escrita violonística abrange publicações sobre transcrições, métodos, manuscritos e composições para o violão.

Os trabalhos que dizem respeito ao ensino e aprendizagem do instrumento foram enquadrados na categoria Pedagogia do violão, na qual encontram-se as seguintes temáticas: ensino coletivo, arranjos didáticos, violão para crianças, violão na educação básica, relatos de experiência pedagógica, entre outros.

$\mathrm{Na}$ categoria Aspectos históricos e biográficos do violão brasileiro, apresentamos os trabalhos que têm, como objeto de estudo, questões biográficas e históricas. Alguns trabalhos dessa categoria levam também em consideração questões estéticas e idiomáticas do instrumento, assim como a produção brasileira para violão no geral.

A categoria Outros consiste na junção dos trabalhos que não se encaixaram em nenhuma das categorias anteriores, e reúne temáticas diversas e menos recorrentes nos dois eventos pesquisados. As categorias e suas respectivas porcentagens de publicaçóes encontram-se representadas na Figura 2:

FIGURA 2 -Artigos por categoria.

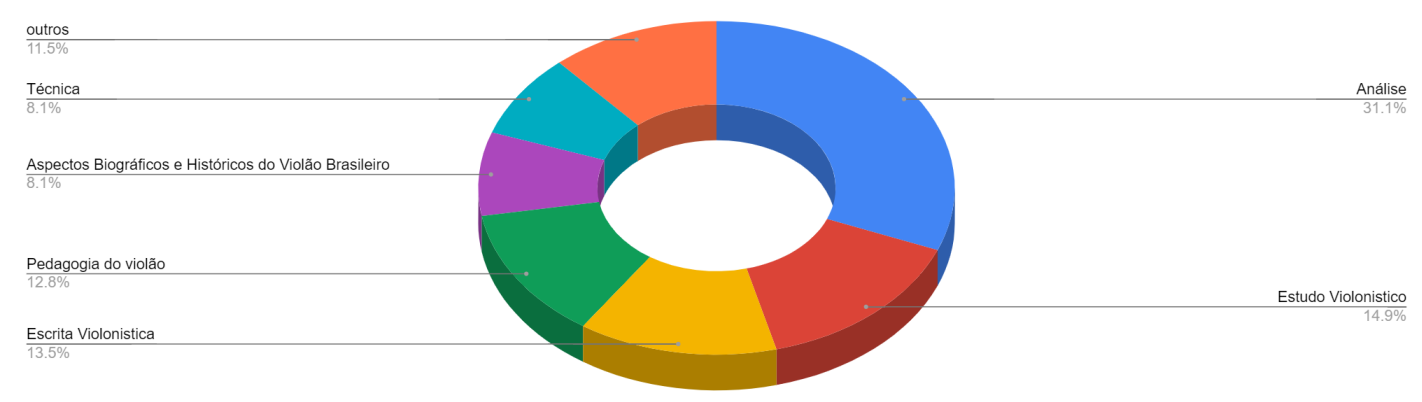

Fonte: Autores

Notamos, pelo gráfico, um certo equilíbrio de publicações entre as categorias estipuladas. A categoria Análise foi a que mais se destacou, com 46 trabalhos, ou seja, 31,1\% das publicações. As demais categorias tiveram de 12 a 22 publicações: 22 na categoria Estudo violonistico; 20 em Escrita violonistica; $19 \mathrm{em}$ Pedagogia do violão; $12 \mathrm{em}$ Técnica; $12 \mathrm{em}$ Aspectos históricos e biográficos do violão brasileiro. A categoria Outros ficou com 17 publicações. A seguir, apresentaremos tabelas com as listas de trabalhos por categorias. 
TABELA 2 - Publicaçôes na categoria Análise

\begin{tabular}{|c|c|c|}
\hline Título & Autor(es) & Evento \\
\hline Casablanca, opus 77 - de Jaime Zenamon - análise da obra & $\begin{array}{l}\text { ALMEIDA; MELLO } \\
(2007)\end{array}$ & EMBAP \\
\hline $\begin{array}{l}\text { Progressão dos conjuntos em Paisaje cubano con campanas, de Leo } \\
\text { Brouwer }\end{array}$ & LIMA (2007) & EMBAP \\
\hline Concerto à brasileira no 4 - Radamés Gnattali (1906-1988) & $\begin{array}{l}\text { FIGUEIREDO } \\
(2007)\end{array}$ & EMBAP \\
\hline $\begin{array}{l}\text { Variaçốes Brouwer: o processo criativo das Variaçôes sobre um tema } \\
\text { de Brouwer, de Leonardo Wilczek }\end{array}$ & WILCZEK (2007) & EMBAP \\
\hline A obra para violão de Camargo Guarnieri & JACOMIN (2008) & EMBAP \\
\hline Uma breve análise da obra El arpa del guerrero de Leo Brouwer & SILVA (2008) & EMBAP \\
\hline $\begin{array}{l}\text { Análise de procedimentos imitativos na obra Electric counterpoint } \\
\text { de Steve Reich }\end{array}$ & MENDES (2008) & EMBAP \\
\hline $\begin{array}{l}\text { Análise retórico-musical das árias Flow my tears e Come, heavy } \\
\text { sleep, de John Dowland (1563-1626) }\end{array}$ & $\begin{array}{l}\text { BURMESTER } \\
(2008)\end{array}$ & EMBAP \\
\hline $\begin{array}{l}\text { Quase uma suíte pós-moderna: análise de Preludio e Quasi una } \\
\text { passacaglia, obras para violáo solo de Gilberto Mendes }\end{array}$ & CIPRIANO (2008) & EMBAP \\
\hline $\begin{array}{l}\text { Concerto para dois violóes, oboé e orquestra, de Radamés Gnattali: as } \\
\text { influências da música folclórica e popular }\end{array}$ & $\begin{array}{l}\text { BARROS; } \\
\text { TENÓRIO (2008) }\end{array}$ & EMBAP \\
\hline Os Doze estudos para violão de Francisco Mignone & $\begin{array}{l}\text { KOLODZIEISKI } \\
(2008)\end{array}$ & EMBAP \\
\hline $\begin{array}{l}\text { O Prelúdio no } 2 \text { para violão de Guerra-Peixe e a trilha sonora do } \\
\text { filme O diabo mora no sangue }\end{array}$ & $\begin{array}{l}\text { VETROMILLA } \\
(2008)\end{array}$ & EMBAP \\
\hline $\begin{array}{l}\text { Radamés Gnattali - Estudo n } 5 \text { para violão solo e suas relações } \\
\text { com a música caipira }\end{array}$ & VIDAL JR. (2008) & EMBAP \\
\hline $\begin{array}{l}\text { Elementos percussivos estruturais: uma abordagem em obras para } \\
\text { violão de Edino Krieger e Arthur Kampela }\end{array}$ & SILVA (2008) & EMBAP \\
\hline $\begin{array}{l}\text { Análise estilística da obra Balada da saudade (1975), do violonista } \\
\text { e compositor Dilermando Reis (1916-1977) }\end{array}$ & MEDEIROS (2009) & EMBAP \\
\hline $\begin{array}{l}\text { Sonata andina de Jaime M. Zenamon: análise do primeiro } \\
\text { movimento }\end{array}$ & TENÓRIO (2009) & EMBAP \\
\hline
\end{tabular}


TABELA 2 - (cont.) Publicações na categoria Análise

\begin{tabular}{|c|c|c|}
\hline Título & Autor(es) & Evento \\
\hline $\begin{array}{l}\text { Desenvolvimento musical para grupo de violóes a partir de ideais } \\
\text { surrealistas oníricos e base na música futurista do século XX }\end{array}$ & LENTZ (2009) & EMBAP \\
\hline $\begin{array}{l}\text { Os Doze estudos para violão de Heitor Villa-Lobos: um confronto } \\
\text { de influências }\end{array}$ & $\begin{array}{l}\text { KOLODZIEISKI } \\
(2009)\end{array}$ & EMBAP \\
\hline $\begin{array}{l}\text { A música popular brasileira na obra para violão solo de Heitor } \\
\text { Villa-Lobos }\end{array}$ & JACOMIN (2009) & EMBAP \\
\hline $\begin{array}{l}\text { O Concerto para violão e orquestra de Francisco Mignone: análise } \\
\text { técnica-interpretativa do primeiro movimento }\end{array}$ & $\begin{array}{l}\text { KOLODZIEISKI e } \\
\text { BARK (2011) }\end{array}$ & EMBAP \\
\hline $\begin{array}{l}\text { The Guitar Chord - an analysis of Alberto Ginastera use of the } \\
\text { guitar as a compositional source on Sonata Op. } 47 \text { for guitar }\end{array}$ & MORAES (2012) & EMBAP \\
\hline $\begin{array}{l}\text { O arranjo de Marco Pereira em My funny valentine: da leadsheet à } \\
\text { peça }\end{array}$ & THOMAZ (2012) & EMBAP \\
\hline $\begin{array}{l}\text { Simples e absurdo: um olhar sobre os aspectos harmônicos da } \\
\text { linguagem composicional de Guinga }\end{array}$ & SILVA (2012) & EMBAP \\
\hline $\begin{array}{l}\text { A utilização do idiomatismo do violão na Ritmata de Edino } \\
\text { Krieger }\end{array}$ & KREUTZ (2012) & EMBAP \\
\hline $\begin{array}{l}\text { Aspectos do choro tradicional presentes nos Choros n. } 1 \text { de Heitor } \\
\text { Villa-Lobos }\end{array}$ & $\begin{array}{l}\text { MANFRINATO } \\
(2013)\end{array}$ & EMBAP \\
\hline $\begin{array}{l}\text { O processo de composição aplicado ao violáo solo em Cueca de } \\
\text { Agustín Barrios, uma análise comparativa }\end{array}$ & GOMES (2013) & EMBAP \\
\hline 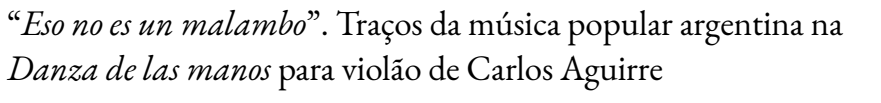 & IRAVEDRA (2013) & EMBAP \\
\hline $\begin{array}{l}\text { Análise para interpretação: entendendo a estruturação temporal } \\
\text { da obra Changes de Elliott Carter }\end{array}$ & KRÜGER (2013) & EMBAP \\
\hline $\begin{array}{l}\text { Estudo para violão n. 10, de Heitor Villa-Lobos: uma análise da } \\
\text { organização temporal }\end{array}$ & $\begin{array}{l}\text { FERNANDES; } \\
\text { SANTOS (2013) }\end{array}$ & EMBAP \\
\hline $\begin{array}{l}\text { Entre o tradicional e o contemporâneo: recursos violonísticos nas } \\
\text { obras de Marcus Siqueira }\end{array}$ & ANTUNES (2013) & EMBAP \\
\hline A música brasileira pelas mãos de Paulo Bellinati & SILVA (2013) & EMBAP \\
\hline
\end{tabular}


TABELA 2 - (cont.) Publicações na categoria Análise

\begin{tabular}{|c|c|c|}
\hline Título & Autor(es) & Evento \\
\hline $\begin{array}{l}\text { Ritmos de gêneros brasileiros na escrita violonística de Marco } \\
\text { Pereira }\end{array}$ & $\begin{array}{l}\text { THOMAZ; } \\
\text { SCARDUELLI } \\
(2013)\end{array}$ & EMBAP \\
\hline $\begin{array}{l}\text { A transcrição de Carlevaro da Chaconne BWV } 1004 \text { de J.S. Bach } \\
\text { comparada com as transcrições de Segovia e Costa: uma análise de } \\
\text { procedimentos representativos }\end{array}$ & $\begin{array}{l}\text { BESCHIZZA; } \\
\text { OROSCO (2015) }\end{array}$ & EMBAP \\
\hline $\begin{array}{l}\text { Estudo comparado das flutuaçốes de andamento em quatro } \\
\text { gravações de Du schönes bäcblein para violão solo de Hans Werner } \\
\text { Henze }\end{array}$ & SILVA (2015) & EMBAP \\
\hline Só nata brasileira no 1 de Waltel Branco: uma análise schenkeriana & BATTISTI (2015) & EMBAP \\
\hline $\begin{array}{l}\text { Campero de las Cinco piezas para guitarra de Astor Piazzolla. } \\
\text { Análisis de cuatro grabaciones basadas en el manuscrito }\end{array}$ & IRAVEDRA (2015) & EMBAP \\
\hline O idiomatismo na obra para violão solo de Sebastião Tapajós & $\begin{array}{l}\text { NASCIMENTO } \\
(2015)\end{array}$ & EMBAP \\
\hline Estudo 11 para violão de Heitor Villa-Lobos: uma macro análise & $\begin{array}{l}\text { SANTOS; } \\
\text { FERNANDES } \\
(2015)\end{array}$ & EMBAP \\
\hline $\begin{array}{l}\text { O tempo musical na obra Tetragrammaton XIII, de Roberto } \\
\text { Victorio }\end{array}$ & ROSA (2015) & EMBAP \\
\hline $\begin{array}{l}\text { London Carapé de Agustín Barrios: algumas questóes contextuais } \\
\text { e métricas }\end{array}$ & $\begin{array}{l}\text { GOMES; } \\
\text { BARBEITAS (2016) }\end{array}$ & ABRAPEM \\
\hline $\begin{array}{l}\text { Aralume, as diversas representações sonoras de uma composição } \\
\text { Armorial }\end{array}$ & DESLANDES (2017) & EMBAP \\
\hline $\begin{array}{l}\text { Estudo comparativo entre duas versôes da música Cheio de dedos, } \\
\text { do compositor Carlos Altier de Souza Lemos Escobar, o Guinga }\end{array}$ & $\begin{array}{l}\text { BARASNEVICIUS; } \\
\text { ANTUNES (2017) }\end{array}$ & EMBAP \\
\hline $\begin{array}{l}\text { Carinhoso, de Pixinguinha: uma análise do arranjo e da } \\
\text { performance de Lula Galvão ao violão solo }\end{array}$ & POLO (2017) & EMBAP \\
\hline $\begin{array}{l}\text { O violão sergipano: o idiomatismo na música para violáo de } \\
\text { Alvino Argollo }\end{array}$ & $\begin{array}{l}\text { SANTOS; MATOS } \\
(2017)\end{array}$ & EMBAP \\
\hline $\begin{array}{l}\text { Explorando o Estudo no } 1 \text { para violão solo de Heitor Villa-Lobos: } \\
\text { suas características idiomáticas e sugestôes de aplicação para além } \\
\text { dos pontos técnicos para o qual foi escrito }\end{array}$ & ALVES (2018) & ABRAPEM \\
\hline Quando Leo Brouwer fez uma homenagem a Villa-Lobos & SILVA; LIRA (2018) & ABRAPEM \\
\hline
\end{tabular}


Nesta categoria, há trabalhos que priorizam o texto musical escrito e os que analisam outros aspectos. Quanto à análise mais centrada do texto musical, esta acontece de forma isolada enquadrando-se no contexto da teoria e análise musical - ou com direcionamento para a performance musical. Os métodos analíticos utilizados foram os seguintes: formal, motívico, retórico-musical, teoria dos conjuntos, estilístico e temporal, entre outros. Os autores propuseram a análise de peças isoladas ou conjunto de peças, bem como a análise comparativa. Salientamos um considerável número de trabalhos que propôs a identificação de elementos da música popular em peças de concerto. Quanto à análise de outros aspectos, pontuamos a análise de gravaçóes, da performance e do idiomatismo; esta última aborda o resultado sonoro da escrita violonística, relacionando-o com as influências estéticas do compositor.

Outra categoria que teve destaque em número de publicações foi Estudo violonistico, com 22 publicaçóes, apresentadas na tabela a seguir:

TABELA 3 - Publicações na categoria Estudo violonistico

\begin{tabular}{|c|c|c|}
\hline Título & Autor(es) & Evento \\
\hline César Guerra-Peixe: Prelúdio No 1 (Lua Cheia) & BARROS (2007) & EMBAP \\
\hline $\begin{array}{l}\text { Leitura musical ao violão: um método focado nas dificuldades de } \\
\text { mudanças de posiçóes }\end{array}$ & BOGO (2007) & EMBAP \\
\hline $\begin{array}{l}\text { Interpretação da música renascentista: a tablatura como apoio para } \\
\text { o intérprete moderno }\end{array}$ & TENÓRIO (2007) & EMBAP \\
\hline $\begin{array}{l}\text { Pesquisa experimental sobre a influência da composição musical, } \\
\text { empregada como estudo deliberado, para a execução do Estudo 1, de } \\
\text { Leo Brouwer }\end{array}$ & AFONSO (2009) & EMBAP \\
\hline Interpretação da música do Classicismo no violão & MADEIRA (2009) & EMBAP \\
\hline $\begin{array}{l}\text { Considerações iniciais sobre leitura à primeira vista, memorização e } \\
\text { a disciplina Percepção Musical }\end{array}$ & OTUTUMI (2011) & EMBAP \\
\hline $\begin{array}{l}\text { Estratégias de estudo para violão: levantamento primário no Portal } \\
\text { de Periódicas da CAPES de pesquisas de Pós-Graduação realizadas } \\
\text { no Brasil de } 1987 \text { a } 2012\end{array}$ & PIRES (2012) & EMBAP \\
\hline $\begin{array}{l}\text { O processo de digitação e dedilhado do tema Assisa a pie d'un salice } \\
\text { da Rossiniana op. } 119 \text { n. } 01 \text { de Mauro Giuliani }\end{array}$ & $\begin{array}{l}\text { SUEIRO JUNIOR; } \\
\text { ALIPIO (2013) }\end{array}$ & EMBAP \\
\hline $\begin{array}{l}\text { O processo de digitação para violão do Prelúdio da Suite IV para } \\
\text { alaúde } B W V 1006 \text { a de Johann Sebastian Bach }\end{array}$ & $\begin{array}{l}\text { SCHMIDT JUNIOR } \\
(2013)\end{array}$ & EMBAP \\
\hline
\end{tabular}


TABELA 3 - (cont.) Publicações na categoria Estudo violonistico

\begin{tabular}{|c|c|c|}
\hline Título & Autor(es) & Evento \\
\hline ¿Cómo estudiar? Consideraciones sobre el estudio de la guitarra & $\begin{array}{l}\text { FERNÁNDEZ E. } \\
(2013)\end{array}$ & EMBAP \\
\hline $\begin{array}{l}\text { Changes (1983) para violão de Elliott Carter: a construção de um } \\
\text { plano de estudo a partir de um auto-relato }\end{array}$ & $\begin{array}{l}\text { PIRES; CARVALHO } \\
\text { (2013) }\end{array}$ & ABRAPEM \\
\hline $\begin{array}{l}\text { Imagens mentais: implicaçóes para o ensino e aprendizagem e para a } \\
\text { leitura à primeira vista do violonista }\end{array}$ & $\begin{array}{l}\text { DONOSO; ARÔXA } \\
(2013)\end{array}$ & EMBAP \\
\hline Leitura à primeira vista na perspectiva de violonistas especialistas & ARÔXA (2013) & EMBAP \\
\hline $\begin{array}{l}\text { Preparação e planejamento da performance do violonista: estudo da } \\
\text { obra Homenagem a Villa-Lobos op. } 46 \text { de Marlos Nobre }\end{array}$ & $\begin{array}{l}\text { KAMINSKI; } \\
\text { AGUIAR (2013) }\end{array}$ & ABRAPEM \\
\hline Aquisição de habilidades rítmicas no estudo do violão & $\begin{array}{l}\text { LOYOLA FILHO } \\
(2013)\end{array}$ & EMBAP \\
\hline $\begin{array}{l}\text { Comunicação gestual em duos de violão: preparação para } \\
\text { performance da obra Micro piezas I de Leo Brouwer }\end{array}$ & $\begin{array}{l}\text { MELLO; KAMINSKI; } \\
\text { RAY (2014) }\end{array}$ & ABRAPEM \\
\hline $\begin{array}{l}\text { Aplicação dos modelos teóricos de Swanwick na performance do } \\
\text { violão erudito }\end{array}$ & SILVA (2015) & EMBAP \\
\hline $\begin{array}{l}\text { Ponteado de Antônio José Madureira: uma concepção interpretativa } \\
\text { sobre a ótica da Música Armorial }\end{array}$ & $\begin{array}{l}\text { RODRIGUES; BOLIS } \\
(2015)\end{array}$ & EMBAP \\
\hline Estratégias para organização da prática individual do violonista & $\begin{array}{l}\text { SANTOS; GLOEDEN } \\
(2015)\end{array}$ & EMBAP \\
\hline $\begin{array}{l}\text { Otimizando a performance violonística: consideraçóes sobre } \\
\text { práticas mentais entre violonistas }\end{array}$ & $\begin{array}{l}\text { MENDONÇA; } \\
\text { MEIRINHOS (2015) }\end{array}$ & EMBAP \\
\hline $\begin{array}{l}\text { O violáo como pequena orquestra: uma proposta interpretativa } \\
\text { sobre a Fantasia op. } 30 \text { de Fernando Sor }\end{array}$ & $\begin{array}{l}\text { ANDRADE; } \\
\text { VINCENS (2015) }\end{array}$ & EMBAP \\
\hline $\begin{array}{l}\text { Duo de violóes: reflexões sobre poética interpretativa, repertório e } \\
\text { digitação }\end{array}$ & $\begin{array}{l}\text { PINHEIRO; BIAGGI } \\
(2016)\end{array}$ & ABRAPEM \\
\hline
\end{tabular}

Fonte: Autores

Essa categoria reúne vários assuntos relacionados ao estudo violonístico, como leitura musical, planejamento e preparação da performance, estratégias para o estudo, interpretação de músicas de diferentes épocas, aquisição de habilidades e propostas interpretativas, entre outros. Destacamos que, dado a natureza dos trabalhos dessa categoria, o leitor, ao estuda-los, possivelmente se informará, de forma bastante prática, acerca de estratégias para a organização da prática individual e camerística ao instrumento. 
Os trabalhos que abordam transcrição, manuscritos, composição, métodos, revisão e tablaturas foram englobados na categoria Escrita violonistica, justamente pela similaridade encontrada entre os assuntos, centrado no texto musical escrito, e encontram-se detalhados na tabela a seguir:

TABELA 4 - Publicações na categoria Escrita violonistica

\begin{tabular}{|c|c|c|}
\hline Título & Autor(es) & Evento \\
\hline $\begin{array}{l}\text { Os } 12 \text { estudos para violão de Villa-Lobos: como os manuscritos podem } \\
\text { interferir na interpretação }\end{array}$ & FRAGA (2007) & EMBAP \\
\hline $\begin{array}{l}\text { Digitação violonística - uma análise crítica e musical das transcriçóes de } \\
\text { Andrés Segovia e Frank Koonce da Fuga BWV } 998 \text { de J. S. Bach }\end{array}$ & ORELLANA (2008) & EMBAP \\
\hline A música indígena e sua função como base de composição para o violão & LENTZ (2008) & EMBAP \\
\hline Transcrições: considerações para uma transcrição coerente & GONTARSKI (2008) & EMBAP \\
\hline 1799 - o ano dos métodos para guitarra de seis ordens & ROMÃO (2011) & EMBAP \\
\hline Experimentos composicionais para grupo de violōes & MENDES (2012) & EMBAP \\
\hline $\begin{array}{l}\text { O processo de transcrição do 1o movimento do Concerto em Sol Maior } \\
B W V 592 \text { para órgão e sua transcrição para cravo (BWV 592a): } \\
\text { resultados parciais de uma pesquisa em andamento }\end{array}$ & $\operatorname{ALMEIDA}(2012)$ & EMBAP \\
\hline $\begin{array}{l}\text { Ciclo nordestino I: um estudo sobre a recriação de Marlos Nobre para } \\
\text { duo de violóes }\end{array}$ & PINHEIRO (2013) & EMBAP \\
\hline $\begin{array}{l}\text { Decisôes interpretativas em Lendas capixabas para violão solo de Carlos } \\
\text { Cruz: subsídios para o estabelecimento de uma edição crítica }\end{array}$ & $\begin{array}{l}\text { SIMÕES; WINTER } \\
(2013)\end{array}$ & ABRAPEM \\
\hline $\begin{array}{l}\text { A obra para violão de Carlos Cruz: uma descrição dos manuscritos } \\
\text { encontrados no acervo do compositor }\end{array}$ & SIMÕES (2013) & EMBAP \\
\hline Guitar multiphonics: notations for a formalized approach & $\begin{array}{l}\text { TORRES; } \\
\text { FERREIRA-LOPES } \\
(2013)\end{array}$ & EMBAP \\
\hline $\begin{array}{l}\text { Prelúdio BWV 998: comparação entre o manuscrito e duas transcrições } \\
\text { conceituadas }\end{array}$ & BARCELOS (2013) & EMBAP \\
\hline $\begin{array}{l}\text { Transcriçôes para voz e violão das cançôes de Alberto Nepomuceno: } \\
\text { traduzindo um nacionalista romântico }\end{array}$ & $\begin{array}{l}\text { BARBEITAS; } \\
\text { CASTRO (2013) }\end{array}$ & EMBAP \\
\hline Processo de transcrição de obras da vihuela para o violão & LACERDA (2013) & EMBAP \\
\hline $\begin{array}{l}\text { O processo de revisão da peça Aberturinhazinha, para violão solo, de } \\
\text { Marcelo Rauta }\end{array}$ & SIMÕES (2015) & EMBAP \\
\hline
\end{tabular}


TABELA 4 - (cont.) Publicações na categoria Escrita violonistica

\begin{tabular}{lll}
\hline \multicolumn{1}{c}{ Título } & \multicolumn{1}{c}{ Autor(es) } & Evento \\
\hline Leitura de tablaturas de vihuela ao violão: relato de pesquisa & AZEVEDO (2015) & EMBAP \\
$\begin{array}{l}\text { Malambo de Salvador Amato: técnicas instrumentais da música } \\
\text { folclórica argentina em um arranjo para contrabaixo e violão }\end{array}$ & $\begin{array}{l}\text { OLIVÁREZ; } \\
\text { MATURRO (2015) }\end{array}$ & EMBAP \\
$\begin{array}{l}\text { O processo de revisão de três movimentos da Suite Chaves, para violão } \\
\text { solo, de Marcelo Rauta }\end{array}$ & SIMÕES (2016) & ABRAPEM \\
$\begin{array}{l}\text { O Método de António da Silva Leite para guitarra inglesa e a circulação } \\
\text { de suas peças no Brasil Oitocentista }\end{array}$ & AMORIM (2017) & EMBAP \\
$\begin{array}{l}\text { Nova transcrição de Noite de lua de Dilermando Reis para violão solo } \\
\text { fundindo a parte dos dois violóes com base na gravação original }\end{array}$ & PEREIRA (2017) & EMBAP \\
\hline
\end{tabular}

Fonte: Autores

A seguir, na categoria Técnica, há trabalhos relacionados ao estudo da técnica violonística em geral, que englobam pestanas, polegar, toque digital, utilização do dedo mínimo, ligados, campanelas, e coordenação bimanual, entre outros, e se encontram discriminados na tabela a seguir:

TABELA 5 - Publicações na categoria Técnica

\begin{tabular}{|c|c|c|}
\hline Título & Autor(es) & Evento \\
\hline $\begin{array}{l}\text { Ampliação da técnica violonística de mão esquerda: um estudo sobre a } \\
\text { pestana }\end{array}$ & $\begin{array}{l}\text { MADEIRA; } \\
\text { SCARDUELLI } \\
(2011)\end{array}$ & EMBAP \\
\hline Gradações do toque digital & BARROS (2012) & EMBAP \\
\hline $\begin{array}{l}\text { Os resultados do estudo de técnica relacionada ao violão de concerto na } \\
\text { performance do músico popular: relato de profissionais }\end{array}$ & $\begin{array}{l}\text { SILVA; } \\
\text { SCARDUELLI } \\
(2013)\end{array}$ & EMBAP \\
\hline $\begin{array}{l}\text { Pesquisa sobre as possibilidades de toque do polegar: estudo baseado nas } \\
\text { escolas violonísticas de Ferdinando Carulli, Fernando Sor e Isaías Sávio }\end{array}$ & AFONSO (2013) & EMBAP \\
\hline $\begin{array}{l}\text { Estudos de Sor e Brouwer: uma abordagem comparativa de demandas } \\
\text { técnicas }\end{array}$ & ALVES (2013) & ABRAPEM \\
\hline $\begin{array}{l}\text { O uso de campanelas e ligados na Suite BWV } 995 \text { para alaúde como } \\
\text { referência para a adaptação de articulaçóes do repertório bachiano ao violão }\end{array}$ & $\operatorname{cosTA}(2013)$ & EMBAP \\
\hline
\end{tabular}


TABELA 5 - (cont.) Publicações na categoria Técnica

\begin{tabular}{lll}
\hline \multicolumn{1}{c}{ Título } & \multicolumn{1}{c}{ Autor(es) } & \multicolumn{1}{c}{ Evento } \\
\hline $\begin{array}{l}\text { Radamés Gnattali: o Concertino n. 2 para violáo e orquestra } \\
\text { e a aplicabilidade do dedo mínimo na técnica da mão direita }\end{array}$ & WIESE (2014) & ABRAPEM \\
$\begin{array}{l}\text { O violão "audaz" de Toninho Horta: um olhar sobre suas aberturas de } \\
\text { acordes formadas através do uso de pestanas com os dedos 2, 3 e 4 }\end{array}$ & $\begin{array}{l}\text { POLO; THOMAZ } \\
(2015)\end{array}$ & EMBAP \\
& & \\
$\begin{array}{l}\text { Estudo Op. 60 n. 2 de Matteo Carcassi: estudo de recursos mecânico- } \\
\text { instrumentais básicos }\end{array}$ & $\begin{array}{l}\text { CANILHA; } \\
\text { GLOEDEN (2015) }\end{array}$ & EMBAP \\
$\begin{array}{l}\text { Um estudo de abordagem didática da pestana na iniciação ao violão sob a } \\
\text { ótica da neutralização técnica e da motivação }\end{array}$ & $\begin{array}{l}\text { RODRIGUES; } \\
\text { CERQUEIRA }\end{array}$ & EMBAP \\
$\begin{array}{l}\text { Os arpejos em Leo Brouwer e Matteo Carcassi: uma análise técnica e } \\
\text { complementação }\end{array}$ & $\begin{array}{l}\text { BRESSAN; } \\
\text { PEREIRA (2017) }\end{array}$ & EMBAP \\
$\begin{array}{l}\text { Coordenação Bimanual ao Violão (CBV): discussão dos resultados de um } \\
\text { experimento piloto com alunos do curso de Licenciatura em Música da } \\
\text { Universidade do Estado do Rio Grande do Norte (UERN) }\end{array}$ & $\begin{array}{l}\text { SIMÕES; WOLFF } \\
\text { (2018) }\end{array}$ & ABRAPEM \\
\hline
\end{tabular}

Fonte: Autores

Estes trabalhos, inicialmente, compunham uma subcategoria de Estudo violonistico; entretanto, com o amadurecimento de nossa pesquisa, percebemos que esta merecia uma categoria à parte, dado o elevado número de publicações específicas sobre técnica instrumental.

A seguir, apresentamos uma lista dos trabalhos inseridos na categoria Pedagogia do violão:

TABELA 6 - Publicações na categoria Pedagogia do violão

\begin{tabular}{llc}
\hline \multicolumn{1}{c}{ Título } & \multicolumn{1}{c}{ Autor(es) } & Evento \\
\hline $\begin{array}{l}\text { Aula de violão nas universidades brasileiras: um olhar a partir de } \\
\text { Perrenoud }\end{array}$ & MARCELINO (2007) & EMBAP \\
$\begin{array}{l}\text { A motivação do aluno no contexto violonístico através do continuum } \\
\text { de autodeterminação - um projeto para pesquisa }\end{array}$ & FIGUEIREDO (2008) & EMBAP \\
$\begin{array}{l}\text { Relato de experiência didática: aulas de violão em grupo } \\
\begin{array}{l}\text { A música de câmara como ferramenta do ensino de violão: uma revisão } \\
\text { de literatura }\end{array}\end{array}$ & FRIGATTI (2009) & EMBAP (2011) \\
\hline
\end{tabular}


TABELA 6 - (cont.) Publicações na categoria Pedagogia do violão

\begin{tabular}{|c|c|c|}
\hline Título & Autor(es) & Evento \\
\hline $\begin{array}{l}\text { Métodos de técnica instrumental criados para violão erudito aplicados } \\
\text { em alunos de violão popular com auxílio da Teoria da Autorregulação: } \\
\text { acompanhamento e análise de resultados }\end{array}$ & SILVA (2012) & EMBAP \\
\hline $\begin{array}{l}\text { Oficina de violão: uma experiência de ensino e aprendizagem com } \\
\text { alunos da educação básica }\end{array}$ & GIRATA (2013) & EMBAP \\
\hline $\begin{array}{l}\text { Ensino de violão para iniciantes: uma reflexão sobre o uso das } \\
\text { tonalidades }\end{array}$ & BRAZIL (2013) & EMBAP \\
\hline $\begin{array}{l}\text { O contraponto das ideias de Murray Schafer e Henrique Pinto para o } \\
\text { estudo e aprendizado do violáo }\end{array}$ & GUIMARÃES (2013) & EMBAP \\
\hline $\begin{array}{l}\text { Estudo de possibilidades de aprendizagem melódica ao violáo através de } \\
\text { arranjos didáticos coletivos }\end{array}$ & $\begin{array}{l}\text { COSTA; } \\
\text { CERQUEIRA (2015) }\end{array}$ & EMBAP \\
\hline $\begin{array}{l}\text { A metodologia de ensino coletivo do violấo no Projeto Prelúdio: uma } \\
\text { construção coletiva }\end{array}$ & GARCIA (2015) & EMBAP \\
\hline $\begin{array}{l}\text { Violão na educação básica: através do ensino coletivo, da rítmica } \\
\text { dalcroziana e tablatura rítmica }\end{array}$ & MODESTO (2015) & EMBAP \\
\hline Isaias Sávio e o violão para as crianças & $\begin{array}{l}\text { SILVA; ZANIN; } \\
\text { COSTA (2015) }\end{array}$ & EMBAP \\
\hline O violão popular brasileiro: procurando possíveis definições & $\begin{array}{l}\text { THOMAZ; } \\
\text { SCARDUELLI (2015) }\end{array}$ & EMBAP \\
\hline $\begin{array}{l}\text { Aplicação pedagógica dos Nuevos estudios sencillos na obra La ciudad de } \\
\text { las columnas, de Leo Brouwer }\end{array}$ & $\begin{array}{l}\text { MORAIS; } \\
\text { SCARDUELLI (2016) }\end{array}$ & ABRAPEM \\
\hline $\begin{array}{l}\text { Reflexóes sobre uma produção de arranjos didáticos vinculada ao } \\
\text { processo de ensino: a experiência dos Trovadores de Santa Cruz de } \\
\text { Minas }\end{array}$ & $\begin{array}{l}\text { SILVA; CERQUEIRA } \\
(2017)\end{array}$ & EMBAP \\
\hline $\begin{array}{l}\text { Estratégias motivadoras para leitura musical à primeira vista: estudo de } \\
\text { caso a partir do contexto da iniciação ao violão }\end{array}$ & $\begin{array}{l}\text { RAMPINELLI; } \\
\text { CERQUEIRA (2017) }\end{array}$ & EMBAP \\
\hline $\begin{array}{l}\text { Peças folclóricas brasileiras associadas ao método Suzuki de violão: } \\
\text { proposta para abordagem de duas peças }\end{array}$ & AGUERA (2017) & EMBAP \\
\hline $\begin{array}{l}\text { Práticas de tocar de ouvido: a escuta como estratégia de aprendizagem } \\
\text { do violão }\end{array}$ & $\begin{array}{l}\text { DOMINGUETI; } \\
\text { CERQUEIRA (2017) }\end{array}$ & EMBAP \\
\hline $\begin{array}{l}\text { O violáo brasileiro popular no contexto formal: reflexóes a partir do } \\
\text { ensino de harmonia, improvisação e arranjo }\end{array}$ & SEVERO (2018) & ABRAPEM \\
\hline
\end{tabular}

Fonte: Autores 
Esta categoria apresenta os trabalhos que tratam sobre o ensino e aprendizagem do violão, da educação básica à universidade, da iniciação à alta performance, em contexto individual e coletivo, e abarcam temas como arranjos didáticos, leitura, música popular, prática de tocar de ouvido, motivação e música de câmara, entre outros.

A seguir, as publicações englobadas pela categoria Aspectos bistóricos e biográficos do violão brasileiro:

TABELA 7 - Publicações na categoria Aspectos históricos e biográficos do violão brasileiro

\begin{tabular}{|c|c|c|}
\hline Título & Autor(es) & Evento \\
\hline $\begin{array}{l}\text { A obra para violáo solo de Almeida Prado: um panorama } \\
\text { histórico, estético e idiomático }\end{array}$ & $\begin{array}{l}\text { SCARDUELLI; } \\
\text { FIORINI (2007) }\end{array}$ & EMBAP \\
\hline Cláudio Menandro: Sombra e água fresca & VIDAL JR. (2007) & EMBAP \\
\hline $\begin{array}{l}\text { Abordagem genealógica de sua majestade, o violonista e compositor } \\
\text { Dilermando Reis (1916-1977) }\end{array}$ & MEDEIROS (2007) & EMBAP \\
\hline $\begin{array}{l}\text { Delsuamy Vivekananda Medeiros (1938-2004): trajetória de um violáo } \\
\text { no Rio Grande do Sul }\end{array}$ & MEDEIROS (2008) & EMBAP \\
\hline $\begin{array}{l}\text { A Suite popular brasileira: um relato sobre a trajetória de Heitor Villa- } \\
\text { Lobos }\end{array}$ & LIMA (2012) & EMBAP \\
\hline $\begin{array}{l}\text { Apontamentos sobre as obras encomendadas por Turíbio Santos: } \\
\text { Ritmata, Momentos I, Livro para seis cordas }\end{array}$ & $\begin{array}{l}\text { EVANGELISTA } \\
(2012)\end{array}$ & EMBAP \\
\hline Introdução a um estudo biográfico de Jaime M. Zenamon & $\begin{array}{l}\text { GRAIN; AGUERA } \\
\text { (2013) }\end{array}$ & EMBAP \\
\hline Repertório brasileiro para violão: estudos & $\begin{array}{l}\text { BRITO; } \\
\text { VETROMILLA } \\
\text { (2013) }\end{array}$ & ABRAPEM \\
\hline $\begin{array}{l}\text { A obra para violão solo de Dilermando Reis: estudo estilístico, } \\
\text { transcrição de gravaçôes e revisão de partituras publicadas }\end{array}$ & CORDEIRO (2013) & ABRAPEM \\
\hline $\begin{array}{l}\text { A relação entre Camargo Guarnieri e os violonistas para os quais } \\
\text { escreveu obras vista a partir de sua correspondência }\end{array}$ & PEREIRA (2013) & EMBAP \\
\hline Uma síntese histórica sobre o violão na cidade de Mossoró-RN & FREIRE (2015) & EMBAP \\
\hline Um olhar sobre a história da atividade violonística em Teresina & $\begin{array}{l}\text { NUNES; LOPES } \\
(2015)\end{array}$ & EMBAP \\
\hline
\end{tabular}


Esta categoria abarca os trabalhos que focam em características históricas e biográficas do violão brasileiro, levando em consideração também os que evidenciam a importância de certas obras brasileiras para o repertório violonístico.

Os trabalhos que não se encaixaram em nenhuma dessas categorias foram incluídos na categoria Outros, e encontram-se detalhados a seguir:

TABELA 8 - Publicações na categoria Outros

\begin{tabular}{|c|c|c|}
\hline Título & Autor(es) & Evento \\
\hline A orquestra de violóes como formação camerística ao violonista & PUPIA (2007) & EMBAP \\
\hline $\begin{array}{l}\text { Sérgio Abreu - poética e herança histórica através de suas transcrições } \\
\text { para violão: relato de uma pesquisa concluída }\end{array}$ & SILVA (2007) & EMBAP \\
\hline Violão preparado & SKROCK (2007) & EMBAP \\
\hline $\begin{array}{l}\text { Consideraçôes sobre a distonia focal e os fundamentos da } \\
\text { técnica/instrumental ao violão }\end{array}$ & $\begin{array}{l}\text { MEDEIROS; } \\
\text { BARCELLOS (2008) }\end{array}$ & EMBAP \\
\hline A música de câmara para violão - duos: breve relato histórico & $\begin{array}{l}\text { ALMEIDA; } \\
\text { MARCELINO (2008) }\end{array}$ & EMBAP \\
\hline $\begin{array}{l}\text { Técnica de Alexander e o violonista: a educação somática, a Técnica de } \\
\text { Alexander como influência do movimento organizacional, às práticas } \\
\text { corporais na área da Música }\end{array}$ & VIEIRA (2008) & EMBAP \\
\hline $\begin{array}{l}\text { O nacionalismo musical na obra de Manuel de Falla e Frederico Garcia } \\
\text { Lorca: as Siete canciones populares españolas e as Canciones españolas } \\
\text { antiguas }\end{array}$ & $\begin{array}{l}\text { MELLO; VIEIRA } \\
(2009)\end{array}$ & EMBAP \\
\hline Visão geral da história da luteria violonística & HUH (2009) & EMBAP \\
\hline $\begin{array}{l}\text { O violão nos trabalhos de pós-graduação defendidos na região Sul do } \\
\text { Brasil }\end{array}$ & ANTUNES (2009) & EMBAP \\
\hline $\begin{array}{l}\text { Reflexões sobre as diferenças entre a formação musical } \\
\text { erudita e a formação musical popular do violonista }\end{array}$ & BOUNY (2011) & EMBAP \\
\hline $\begin{array}{l}\text { A luteria da guitarra barroca: notas sobre suas especificidades e } \\
\text { construção }\end{array}$ & $\begin{array}{l}\text { PEREIRA; } \\
\text { BERGMANN FILHO } \\
(2012)\end{array}$ & EMBAP \\
\hline $\begin{array}{l}\text { Conservatório Maestro Paulino Martins Alves: um perfil de seus } \\
\text { alunos de violão }\end{array}$ & GLOMBA (2012) & EMBAP \\
\hline $\begin{array}{l}\text { A dinastia Hermann Hauser e sua influência no desenvolvimento da } \\
\text { manufatura do violão: um breve histórico }\end{array}$ & APRO (2013) & EMBAP \\
\hline
\end{tabular}


TABELA 8 - (cont.) Publicaçóes na categoria Outros

\begin{tabular}{lll}
\hline \multicolumn{1}{c}{ Título } & \multicolumn{1}{c}{ Autor(es) } & Evento \\
\hline Gênero, formação e trabalho: um survey com professores de violão & FIGUEIREDO (2015) & EMBAP \\
Catálogo do repertório para violão preparado & MADEIRA (2015) & EMBAP \\
$\begin{array}{l}\text { The uniquely complex bimanual task of classical guitar performance: a } \\
\text { developing experiment for examining instrument-specific } \\
\text { interhemispheric inhibition in guitarists }\end{array}$ & BRANDON (2017) & EMBAP \\
$\begin{array}{l}\text { Violão na Luteria UFPR: ensino da construção e pesquisas sobre o } \\
\text { instrumento }\end{array}$ & FREITAS; FOMIN; & EMBAP \\
\hline
\end{tabular}

Fonte: Autores

Dentre os diversos assuntos presentes nessa categoria, salientamos os seguintes: luteria, formação musical, perfil de alunos e professores, violão nos trabalhos de pós-graduação, violão preparado, inserção do violonista na música de câmara, Técnica de Alexander e distonia focal, entre outros. Nessa categoria, houve uma maior evidência de trabalhos sobre luteria.

\section{Considerações finais}

Em nosso processo de organização dos trabalhos sobre violão identificados nos anais do Simpósio Acadêmico de Violão da EMBAP e do Congresso da ABRAPEM, observamos um certo equilíbrio quantitativo entre as categorias propostas (Análise, Estudo violonistico, Escrita violonistica, Pedagogia do violão, Aspectos biográficos e históricos do violão brasileiro e Técnica), cada qual com uma notável diversidade de temas relevantes, o que representa uma ampla perspectiva de abordagens sobre o violão.

Por outro lado, constatamos que os eventos em questão apresentaram pouquíssimas publicações, ou mesmo nenhuma, sobre temas emergentes de grande importância, como colaboração intérprete-compositor, saúde do músico, estudo mental, tecnologias digitais e perfil de egressos de cursos técnicos e de graduação. Notamos também que parte considerável dos trabalhos consistem em relatos/esforços mais individualizados, localizados, o que é característico de uma área (e também subáreas e temáticas) ainda em processo de consolidação no meio acadêmico brasileiro. 
Ainda assim, conseguimos identificar algumas tendências, mesmo que ainda discretas, como: análise de traços de gêneros populares em peças de concerto na categoria Análise; estratégias de estudo (muitas vezes de peças específicas) e leitura de partituras em Estudo violonistico; transcrições para o violão em Escrita violonistica; pestanas em Técnica; ensino coletivo em Pedagogia do violão.

O panorama traçado neste trabalho consiste em uma contribuição para a área, e poderá propiciar a fundamentação de trabalhos futuros. Sugerimos, a partir da nossa experiência, que sejam realizadas pesquisas bibliográficas sobre o violão em dimensões mais ampliadas, como nos periódicos nacionais e outros eventos, ou que seja atualizado o banco de dados de teses e dissertaçóes sobre o instrumento.

\section{REFERÊNCIAS}

AFONSO, Felipe dos Anjos. Pesquisa sobre as possibilidades de toque do polegar baseado nas escolas violonísticas de Ferdinando Carulli, Fernando Sor e Isaias Sávio. SIMPÓSIO ACADÊMICO DE VIOLÃO DA EMBAP, VII, 2013, Curitiba. Anais... Curitiba: EMBAP, 2013. 57-63.

AFONSO, Felipe dos Anjos. Pesquisa experimental sobre a influência da composição musical, empregada como estudo deliberado, para a execução do Estudo 1, de Leo Brouwer. SIMPÓSIO ACADÊMICO DE VIOLÃO DA EMBAP, 3, 2009, Curitiba. Anais... Curitiba: EMBAP, 2009. 1-20.

AGUERA, Fernando. Peças folclóricas brasileiras associadas ao método Suzuki de violão: propostas para abordagem de duas peças. SIMPÓSIO ACADÊMICO DE VIOLÃO DA EMBAP, IX, 2017, Curitiba. Anais... Curitiba: EMBAP, 2017. 40-48.

ALMEIDA, Cosme Luis de. O processo de transcrição do 1o movimento do Concerto em Sol Maior $B W V 592$ para órgão e sua transcrição para cravo (BWV 592a): resultados parciais de uma pesquisa em andamento. SIMPÓSIO ACADÊMICO DE VIOLÃO DA EMBAP, VI, 2012, Curitiba. Anais... Curitiba: EMBAP, 2012. 1-12.

ALMEIDA, Cosme Luis de; MELLO, Luiz Henrique Rossatto de. Casablanca, opus 77 - de Jaime Zenamon - análise da obra. SIMPÓSIO ACADÊMICO DE VIOLÃO DA EMBAP, I, 2007, Curitiba. Anais... Curitiba: EMBAP, 2007. 1-16.

ALMEIDA, Cosme Luis de; MARCELINO, Eldade Moreira. A música de câmara para violão duos: breve relato histórico. SIMPÓSIO ACADÊMICO DE VIOLÃO DA EMBAP, II, 2008, Curitiba. Anais... Curitiba: EMBAP, 2008. 294-303.

ALVES, Flávia Domingues. Estudos de Sor e Brouwer: uma abordagem comparativa de demandas 
técnicas. CONGRESSO DA ASSOCIAÇÃO BRASILEIRA DE PERFORMANCE MUSICAL, I, 2013, Porto Alegre. Anais... Porto Alegre: ABRAPEM, 2013. 1-12.

ALVES, Raphaell Mota. Explorando o Estudo no 1 para violão solo de Heitor Villa-Lobos: suas características idiomáticas e sugestôes de aplicação para além dos pontos técnicos para o qual foi escrito. CONGRESSO DA ASSOCIAÇÃO BRASILEIRA DE PERFORMANCE MUSICAL, IV, 2018, Natal. Anais... Natal: ABRAPEM, 2018. 201-208.

AMORIM, Humberto. O Método de António da Silva Leite para guitarra inglesa e a circulação de suas peças no Brasil Oitocentista. SIMPÓSIO ACADÊMICO DE VIOLÃO DA EMBAP, IX, 2017, Curitiba. Anais... Curitiba: EMBAP, 2017. 49-62.

ANDRADE, Jefrey Antonio de; VINCENS, Guilherme Caldeira Loss. O violão como pequena orquestra: uma proposta interpretativa sobre a Fantasia op. 30 de Fernando Sor. SIMPÓSIO ACADÊMICO DE VIOLÃO DA EMBAP, VIII, 2015, Curitiba. Anais... Curitiba: EMBAP, 2015. 154-166.

ANTUNES, Gilson . Entre o tradicional e o contemporâneo: recursos violonísticos nas obras de Marcus Siqueira. SIMPÓSIO ACADÊMICO DE VIOLÃO DA EMBAP, VII, 2013, Curitiba. Anais... Curitiba: EMBAP, 2013. 98-107.

ANTUNES, Gilson Uehara Gimenes. O violão nos programas de pós-graduação e na sala de aula: amostragem e possibilidades. 2012. Tese (Doutorado, Música). Universidade de São Paulo, São Paulo, 2012.

ANTUNES, Gilson. O violão nos trabalhos de pós-graduação defendidos na região Sul do Brasil. SIMPÓSIO ACADÊMICO DE VIOLÃO DA EMBAP, 3, 2009, Curitiba. Anais... Curitiba: EMBAP, 2009. 1-12.

APRO, Flávio. A dinastia Hermann Hauser e sua influência no desenvolvimento da manufatura do violão: um breve histórico. SIMPÓSIO ACADÊMICO DE VIOLÃO DA EMBAP, VII, 2013, Curitiba. Anais... Curitiba: EMBAP, 2013.77-84.

ARÔXA, Ricardo. Leitura à primeira vista na perspectiva de violonistas especialistas. SIMPÓSIO ACADÊMICO DE VIOLÃO DA EMBAP, VII, 2013, Curitiba. Anais... Curitiba: EMBAP, 2013. 250-262.

AZEVEDO, Alexandre Santos de. Leitura de tablaturas de vihuela ao violão: relato de pesquisa. SIMPÓSIO ACADÊMICO DE VIOLÃO DA EMBAP, VIII, 2015, Curitiba. Anais... Curitiba: EMBAP, 2015. 26-38.

BARASNEVICIUS, Ivan Daniel; ANTUNES, Gilson Uehara Gimenes. Estudo comparativo entre duas versões da música Cheio de dedos, do compositor Carlos Altier de Souza Lemos Escobar, o Guinga. SIMPÓSIO ACADÊMICO DE VIOLÃO DA EMBAP, IX, 2017, Curitiba. Anais... Curitiba: EMBAP, 2017. 63-74.

BARBEITAS, Flavio; CASTRO, Luciana Monteiro de. Transcriçôes para voz e violão das cançóes de Alberto Nepomuceno: traduzindo um nacionalista romântico. SIMPÓSIO ACADÊMICO DE 
VIOLÃO DA EMBAP, VII, 2013, Curitiba. Anais... Curitiba: EMBAP, 2013. 85-97.

BARCELOS, Jean Francisco. Prelúdio BWV 998: comparação entre o manuscrito e duas transcrições conceituadas. SIMPÓSIO ACADÊMICO DE VIOLÃO DA EMBAP, VII, 2013, Curitiba. Anais... Curitiba: EMBAP, 2013. 1-10.

BARROS, Aluísio Coelho de. César Guerra-Peixe: Prelúdio n 1 (Lua Cheia). SIMPÓSIO ACADÊMICO DE VIOLÃO DA EMBAP, I, 2007, Curitiba. Anais... Curitiba: EMBAP, 2007. 113.

BARROS, Nicolas de Souza. Gradações do toque digital. SIMPÓSIO ACADÊMICO DE VIOLÃO DA EMBAP, VI, 2012, Curitiba. Anais... Curitiba: EMBAP, 2012. 1-20.

BARROS, Aluísio C.; TENÓRIO, Luciana E. L. Concerto para dois violóes, oboé e orquestra, de Radamés Gnattali: as influências da música folclórica e popular. SIMPÓSIO ACADÊMICO DE VIOLÃO DA EMBAP, II, 2008, Curitiba. Anais... Curitiba: EMBAP, 2008. 215-228.

BATTISTI, Dayane. Só nata brasileira no 1 de Waltel Branco: uma análise schenkeriana. SIMPÓSIO ACADÊMICO DE VIOLÃO DA EMBAP, 2015, Curitiba. Anais... Curitiba: EMBAP, 2015. 70-80.

BESCHIZZA, Christhian; OROSCO, Maurício. A transcrição de Carlevaro da Chaconne BWV 1004 de J.S. Bach comparada com as transcriçôes de Segovia e Costa: uma análise de procedimentos representativos. SIMPÓSIO ACADÊMICO DE VIOLÃO DA EMBAP, VIII, 2015, Curitiba. Anais... Curitiba: EMBAP, 2015. 56-69.

BOGO, Danilo. Leitura musical ao violão: um método focado nas dificuldades de mudança de posiçôes. SIMPÓSIO ACADÊMICO DE VIOLÃO DA EMBAP, I, 2007, Curitiba. Anais... Curitiba: EMBAP, 2007. 1-12.

BOUNY, Elodie. Reflexões sobre as diferenças entre a formação musical erudita e a formação musical popular do violonista. SIMPÓSIO ACADÊMICO DE VIOLÃO DA EMBAP, V, 2011, Curitiba. Anais... Curitiba: EMBAP, 2011. 1-14.

BRANDON, Amy. The uniquely complex bimanual task of classical guitar performance: a developing experiment for examining instrument-specific interhemispheric inhibition in guitarists. SIMPÓSIO ACADÊMICO DE VIOLÃO DA EMBAP, IX, 2017, Curitiba. Anais... Curitiba: EMBAP, 2017. 144-149.

BRAZIL, Marcelo. Ensino de violão para iniciantes: uma reflexão sobre o uso das tonalidades. SIMPÓSIO ACADÊMICO DE VIOLÃO DA EMBAP, VII, 2013, Curitiba. Anais... Curitiba: EMBAP, 2013. 162-171.

BRESSAN, Caio Cezar Braga; PEREIRA, Marcelo Fernandes. Os arpejos em Leo Brouwer e Matteo Carcassi: uma análise técnica e complementação. SIMPÓSIO ACADÊMICO DE VIOLÃO DA EMBAP, IX, 2017, Curitiba. Anais... Curitiba: EMBAP, 2017. 16-27.

BRITO, Roberto de; VETROMILLA, Clayton. Repertório brasileiro para violão: estudos. 
Congresso da Associação Brasileira de Performance Musical, I, 2013, Porto Alegre. Anais... Natal: ABRAPEM, 2013. 1-6.

BURMESTER, Haroldo Roger Benghi. Análise retórico-musical das árias Flow my tears e Come, heavy sleep, de John Dowland (1563-1626). SIMPÓSIO ACADÊMICO DE VIOLÃO DA EMBAP, II, 2008, Curitiba. Anais... Curitiba: EMBAP, 2008. 165-185.

CANDEMIL, Luciano da Silva. Panorama das pesquisas sobre a música do candomblé. Opus, v. 25, n. 1, 94-120, 2019.

CANILHA, Cauã Borges; GLOEDEN, Edelton. Estudo Op. 60 n. 2 de Matteo Carcassi: estudo de recursos mecânico-instrumentais básicos. SIMPÓSIO ACADÊMICO DE VIOLÃO DA EMBAP, VIII, 2015, Curitiba. Anais... Curitiba: EMBAP, 2015. 45-55.

CIL, Luciano Ribeiro; GONÇALVES, Taísa Grasiela Gomes Liduenha. Educação musical e educação especial na produção científica de dissertações e teses. Música Hodie, v. 18, n. 2, 327-342, 2018.

CIPRIANO, Luis Alberto Garcia. Quase uma suíte pós-moderna: análise de Preludio e Quase una passacaglia, obras para violão solo de Gilberto Mendes. SIMPÓSIO ACADÊMICO DE VIOLÃO DA EMBAP, II, 2008, Curitiba. Anais... Curitiba: EMBAP, 2008. 90-108.

CORDEIRO, Alessandro Borges. A obra para violão solo de Dilermando Reis: estudo estilístico, transcrições de gravações e revisão de partituras publicadas. Congresso da Associação Brasileira de Performance Musical, I, 2013, Porto Alegre. Anais... Natal: ABRAPEM, 2013. 1-8.

COSTA, Gustavo Silveira. O uso de campanelas e ligados na Suite BWV 995 para alaúde como referência para a adaptação de articulaçôes do repertório bachiano ao violão. SIMPÓSIO ACADÊMICO DE VIOLÃO DA EMBAP, VII, 2013, Curitiba. Anais... Curitiba: EMBAP, 2013. 108-120.

COSTA, Jean Carlos Gomes da; CERQUEIRA, Vladmir Agostini. Estudo de possibilidades de aprendizagem melódica ao violão através de arranjos didáticos coletivos. SIMPÓSIO ACADÊMICO DE VIOLÃO DA EMBAP, VIII, 2015, Curitiba. Anais... Curitiba: EMBAP, 2015. 142-153.

DESLANDES, Sérgio. Aralume, as diversas representações sonoras de uma composição Armorial. SIMPÓSIO ACADÊMICO DE VIOLÃO DA EMBAP, IX, 2017, Curitiba. Anais... Curitiba: EMBAP, 2017. 75-88.

DOMINGUETI, Francisco Bueno; CERQUEIRA, Vladmir Agostini. Práticas de tocar de ouvido: a escuta como estratégia de aprendizado do violão. SIMPÓSIO ACADÊMICO DE VIOLÃO DA EMBAP, IX, 2017, Curitiba. Anais... Curitiba: EMBAP, 2017. 120-133.

DONOSO, Pablo; ARÔXA, Ricardo. Imagens mentais: implicações para o ensino e aprendizagem e para a leitura à primeira vista do violonista. SIMPÓSIO ACADÊMICO DE VIOLÃO DA EMBAP, VII, 2013, Curitiba. Anais... Curitiba: EMBAP, 2013. 197-207. 
EVANGELISTA, Eric Henrique Moreira. Apontamentos sobre as obras encomendadas por Turíbio Santos: Ritmata, Momentos I, Livro para seis cordas. SIMPÓSIO ACADÊMICO DE VIOLÃO DA EMBAP, VI, 2012, Curitiba. Anais... Curitiba: EMBAP, 2012. 1-13.

FANTINI, Renata Franco Severo; JOLY, Ilza Zenker Leme; ROSE, Tânia Maria Santana de. Educação musical especial: produção brasileira nos últimos 30 anos. Revista da ABEM, Londrina, v. 24, n. 36, 36-54, 2016.

FERNANDES, José Nunes. Pesquisa em Educação Musical: situação do campo nas dissertaçóes e teses dos cursos de pós-graduação stricto sensu em Educação. Opus, no 6, 1-14, 1999.

FERNANDES, José Nunes. Pesquisa em Educação Musical: situação do campo nas dissertações e teses dos cursos de pós-graduação stricto sensu em Educação. Revista da ABEM, no 5, 45-58, 2000.

FERNANDES, José Nunes. Pesquisa em Educação Musical: situação do campo nas dissertações e teses dos cursos de pós-graduação stricto sensu brasileiros. Revista da ABEM, no 15, 11-26, 2006.

FERNANDES, Stanley Levi Nazareno; SANTOS, Marcos Antônio Silva. Estudo para violão n. 10, de Heitor Villa-Lobos: uma análise da organização temporal. SIMPÓSIO ACADÊMICO DE VIOLÃO DA EMBAP, VII, 2013, Curitiba. Anais... Curitiba: EMBAP, 2013. 295-311.

FERNÁNDEZ E., Roberto L. ¿Cómo estudiar? Consideraciones sobre el estúdio de la guitarra. SIMPÓSIO ACADÊMICO DE VIOLÃO DA EMBAP, VII, 2013, Curitiba. Anais... Curitiba: EMBAP, 2013. 282-294.

FIGUEIREDO, Edson A. F. Gênero, formação e trabalho: um survey com professores de violão. SIMPÓSIO ACADÊMICO DE VIOLÃO DA EMBAP, VIII, 2015, Curitiba. Anais... Curitiba: EMBAP, 2015. 81-88.

FIGUEIREDO, Edson. Concerto à brasileira no 4 - Radamés Gnattali (1906-1988). SIMPÓSIO ACADÊMICO DE VIOLÃO DA EMBAP, I, 2007, Curitiba. Anais... Curitiba: EMBAP, 2007. 114.

FIGUEIREDO, Edson. A motivação do aluno no contexto violonístico através do continuum de autodeterminação - um projeto para pesquisa. SIMPÓSIO ACADÊMICO DE VIOLÃO DA EMBAP, II, 2008, Curitiba. Anais... Curitiba: EMBAP, 2008. 74-89.

FRAGA, Orlando. Os 12 estudos para violão de Villa-Lobos: como os manuscritos podem interferir na interpretação. SIMPÓSIO ACADÊMICO DE VIOLÃO DA EMBAP, I, 2007, Curitiba. Anais... Curitiba: EMBAP, 2007. 1-34.

FREIRE, Francisco Ronildo. Uma síntese histórica sobre o violão na cidade de Mossoró-RN. SIMPÓSIO ACADÊMICO DE VIOLÃO DA EMBAP, VIII, 2015, Curitiba. Anais... Curitiba: EMBAP, 2015. 123-130.

FREITAS, Thiago Corrêa de; FOMIN, Igor Mottinha; ZACZÉSKI, Monicky Ellys. Violão na Luteria UFPR: ensino da construção e pesquisas sobre o instrumento. SIMPÓSIO ACADÊMICO DE VIOLÃO DA EMBAP, IX, 2017, Curitiba. Anais... Curitiba: EMBAP, 2017. 100-106. 
FRIGATTI, Eduardo Fabrício. Relato de experiência didática: aulas de violão em grupo. SIMPÓSIO ACADÊMICO DE VIOLÃO DA EMBAP, 3, 2009, Curitiba. Anais... Curitiba: EMBAP, 2009. 1-5.

GARCIA, Fernanda Krüger. A metodologia de ensino coletivo do violão no Projeto Prelúdio: uma construção coletiva. SIMPÓSIO ACADÊMICO DE VIOLÃO DA EMBAP, VIII, 2015, Curitiba. Anais... Curitiba: EMBAP, 2015. 99-110.

GIL, Antonio Carlos. Como elaborar projetos de pesquisa. 4a ed. São Paulo: Atlas, 2002.

GIRATA, Paulo Yutaka Toyoshima. Oficina de violão: uma experiência de ensino e aprendizagem com alunos da educação básica. SIMPÓSIO ACADÊMICO DE VIOLÃO DA EMBAP, VII, 2013, Curitiba. Anais... Curitiba: EMBAP, 2013. 208-216.

GLOMBA, Elizeu. Conservatório Maestro Paulino Martins Alves: um perfil de seus alunos de violão. SIMPÓSIO ACADÊMICO DE VIOLÃO DA EMBAP, VI, 2012, Curitiba. Anais... Curitiba: EMBAP, 2012. 1-19.

GOMES, Carlos Alfeu Guerra. O processo de composição aplicado ao violão solo em Cueca de Agustín Barrios, uma análise comparativa. SIMPÓSIO ACADÊMICO DE VIOLÃO DA EMBAP, VII, 2013, Curitiba. Anais... Curitiba: EMBAP, 2013. 26-36.

GOMES, Carlos Alfeu Guerra; BARBEITAS, Flávio Terrigno. London Carapé de Agustín Barrios: algumas questôes contextuais e métricas. CONGRESSO DA ASSOCIAÇÃO BRASILEIRA DE PERFORMANCE MUSICAL, IV, 2016, Campinas. Anais... Campinas: ABRAPEM, 2016. 6575.

GONTARSKI, Luis Cesar. Transcrições: considerações para uma transcrição coerente. SIMPÓSIO ACADÊMICO DE VIOLÃO DA EMBAP, II, 2008, Curitiba. Anais... Curitiba: EMBAP, 2008. 192-202.

GRAIN, Matheus Rocha; AGUERA, Fernando. Introdução a um estudo biográfico de Jaime M. Zenamon. SIMPÓSIO ACADÊMICO DE VIOLÃO DA EMBAP, VII, 2013, Curitiba. Anais... Curitiba: EMBAP, 2013. 181-188.

GUIMARÃES, William Pallazo. O contraponto das ideias de Murray Schafer e Henrique Pinto para o estudo e aprendizado do violão. SIMPÓSIO ACADÊMICO DE VIOLÃO DA EMBAP, VII, 2013, Curitiba. Anais... Curitiba: EMBAP, 2013. 337-343.

HUH, Samuel. Visão geral da história da luteria violonística. SIMPÓSIO ACADÊMICO DE VIOLÃO DA EMBAP, 3, 2009, Curitiba. Anais... Curitiba: EMBAP, 2009. 1-14.

IRAVEDRA, Rafael. “Eso no es un malambo”. Traços de música popular argentina na Danza de las manos para violão de Carlos Aguirre. SIMPÓSIO ACADÊMICO DE VIOLÃO DA EMBAP, VII, 2013, Curitiba. Anais... Curitiba: EMBAP, 2013. 217-228.

IRAVEDRA, Rafael. Campero de las Cinco piezas para guitarra de Astor Piazzolla. Análisis de cuatro grabaciones basadas en el manuscrito. SIMPÓSIO ACADÊMICO DE VIOLÃO DA 
EMBAP, 2015, Curitiba. Anais... Curitiba: EMBAP, 2015. 230-239.

JACOMIN, Vinícius. A música popular brasileira na obra para violão solo de Heitor Villa-Lobos. SIMPÓSIO ACADÊMICO DE VIOLÃO DA EMBAP, 3으, 2009, Curitiba. Anais... Curitiba: EMBAP, 2009. 1-10.

JACOMIN, Vinícius. A obra para violão de Camargo Guarnieri. SIMPÓSIO ACADÊMICO DE VIOLÃO DA EMBAP, II, 2008, Curitiba. Anais... Curitiba: EMBAP, 2008. 209-214

KAMINSKI, Leonardo Casarin; AGUIAR, Werner. Preparação e planejamento da performance do violonista: estudo da obra Homenagem a Villa-Lobos op. 46 de Marlos Nobre. CONGRESSO DA ASSOCIAÇÃO BRASILEIRA DE PERFORMANCE MUSICAL, I, 2013, Campinas. Anais... Campinas: ABRAPEM, 2013. 1e

KOLODZIEISKI, Allan. Os Doze estudos para violão de Francisco Mignone. SIMPÓSIO ACADÊMICO DE VIOLÃO DA EMBAP, II, 2008, Curitiba. Anais... Curitiba: EMBAP, 2008. 203-208.

KOLODZIEISKI, Allan. Os Doze estudos para violão de Heitor Villa-Lobos: um confronto de influências. SIMPÓSIO ACADÊMICO DE VIOLÃO DA EMBAP, 3o, 2009, Curitiba. Anais... Curitiba: EMBAP, 2009. 1-4.

KOLODZIEISKI, Allan; BARK, Josely Maria Machado. O Concerto para violão e orquestra de Francisco Mignone: análise técnica-interpretativa do primeiro movimento. SIMPÓSIO ACADÊMICO DE VIOLÃO DA EMBAP, V, 2011, Curitiba. Anais... Curitiba: EMBAP, 2011. 118.

KREUTZ, Thiago de Campos. A utilização do idiomatismo do violão na Ritmata de Edino Krieger. SIMPÓSIO ACADÊMICO DE VIOLÃO DA EMBAP, VI, 2012, Curitiba. Anais... Curitiba: EMBAP, 2012. 1-17.

KRÜGER, Igor Mendes. Análise para interpretação: entendendo a estruturação temporal da obra Changes de Elliott Carter. SIMPÓSIO ACADÊMICO DE VIOLÃO DA EMBAP, VII, 2013, Curitiba. Anais... Curitiba: EMBAP, 2013. 132-141.

LACERDA, Felipe Damato de. Processo de transcrição de obras da vihuela para o violão. SIMPÓSIO ACADÊMICO DE VIOLÃO DA EMBAP, VII, 2013, Curitiba. Anais... Curitiba: EMBAP, 2013. 64-76.

LAKATOS, Eva Maria; MARCONI, Marina de Andrade. Metodologia do trabalho cientifico: procedimentos básicos, pesquisa bibliográfica, projeto e relatório, publicaçóes e trabalhos científicos. São Paulo: Atlas, 1992.

LENTZ, Willian Marcel Cordeiro. A música indígena e sua função como base de composição para violão. SIMPÓSIO ACADÊMICO DE VIOLÃO DA EMBAP, II, 2008, Curitiba. Anais... Curitiba: EMBAP, 2008. 334-414.

LENTZ, Willian Marcel Cordeiro. Desenvolvimento musical para grupo de violóes a partir de ideais 
surrealistas oníricos e base da música futurista do século XX. SIMPÓSIO ACADÊMICO DE VIOLÃO DA EMBAP, 3, 2009, Curitiba. Anais... Curitiba: EMBAP, 2009. 1-29.

LIMA, Daniel de. Progressão dos conjuntos em Paisaje cubano com campanas, de Leo Brouwer. SIMPÓSIO ACADÊMICO DE VIOLÃO DA EMBAP, I, 2007, Curitiba. Anais... Curitiba: EMBAP, 2007. 1-14.

LIMA, Lurian José Reis da Silva. A Suite popular brasileira: um relato sobre a trajetória de Heitor Villa-Lobos. SIMPÓSIO ACADÊMICO DE VIOLÃO DA EMBAP, VI, 2012, Curitiba. Anais... Curitiba: EMBAP, 2012. 1-10.

LOYOLA FILHO, Luiz Carlos Martins. Aquisição de habilidades rítmicas no estudo do violão. SIMPÓSIO ACADÊMICO DE VIOLÃO DA EMBAP, VII, 2013, Curitiba. Anais... Curitiba: EMBAP, 2013. 152-161.

MADEIRA, Bruno. Catálogo do repertório para violão preparado. SIMPÓSIO ACADÊMICO DE VIOLÃO DA EMBAP, VIII, 2015, Curitiba. Anais... Curitiba: EMBAP, 2015. 39-44.

MADEIRA, Bruno. Interpretação da música do Classicismo no violão. SIMPÓSIO ACADÊMICO DE VIOLÃO DA EMBAP, 3o, 2009, Curitiba. Anais... Curitiba: EMBAP, 2009. 1-20.

MADEIRA, Bruno; SCARDUELLI, Fabio. Ampliação da técnica violonística de mão esquerda: um estudo sobre a pestana. SIMPÓSIO ACADÊMICO DE VIOLÃO DA EMBAP, V, 2011, Curitiba. Anais... Curitiba: EMBAP, 2011. 1-11.

MANFRINATO, Ana Carolina. Aspectos do choro tradicional presentes no Choros n. 1 de Heitor Villa-Lobos. SIMPÓSIO ACADÊMICO DE VIOLÃO DA EMBAP, VII, 2013, Curitiba. Anais... Curitiba: EMBAP, 2013. 10-17.

MARCELINO, Eldade Moreira. Aula de violão nas universidades brasileiras: um olhar a partir de Perrenoud. SIMPÓSIO ACADÊMICO DE VIOLÃO DA EMBAP, I, 2007, Curitiba. Anais... Curitiba: EMBAP, 2007. 1-8.

MEDEIROS, Alan Rafael de. Abordagem genealógica de sua majestade, o violonista e compositor Dilermando Reis (1916-1977). SIMPÓSIO ACADÊMICO DE VIOLÃO DA EMBAP, I, 2007, Curitiba. Anais... Curitiba: EMBAP, 2007. 1-21.

MEDEIROS, Alan Rafael de. Análise estilística da obra Balada da saudade (1975), do violonista e compositor Dilermando Reis (1916-1977). SIMPÓSIO ACADÊMICO DE VIOLÃO DA EMBAP, III, 3o, 2009, Curitiba. Anais... Curitiba: EMBAP, 2009. 1-20.

MEDEIROS, Daniel Ribeiro. Delsuamy Vivekananda Medeiros (1938-2004): trajetória de um violão no Rio Grande do Sul. SIMPÓSIO ACADÊMICO DE VIOLÃO DA EMBAP, 3o, 2009, Curitiba. Anais... Curitiba: EMBAP, 2009. 1-22

MEDEIROS, Daniel Ribeiro; BARCELLOS, Cristina. Consideraçôes sobre a distonia focal e os fundamentos da técnica/instrumental ao violão. SIMPÓSIO ACADÊMICO DE VIOLÃO DA 
EMBAP, II, 2008, Curitiba. Anais... Curitiba: EMBAP, 2008. 281-293.

MELLO, Felipe Marques de; KAMINSKI, Leonardo Casarin; RAY, Sonia. Comunicação gestual em duos de violão: preparação para performance da obra Micro piezas I de Leo Brouwer. CONGRESSO DA ASSOCIAÇÃO BRASILEIRA DE PERFORMANCE MUSICAL, II, 2014, Vitória. Anais... Vitória: ABRAPEM, 2014. 66-72.

MELLO, Luiz Henrique; VIEIRA, Manuela. O nacionalismo musical na obra de Manuel de Falla e Frederico Garcia Lorca: as Siete canciones populares españolas e as Canciones españolas antiguas. SIMPÓSIO ACADÊMICO DE VIOLÃO DA EMBAP, 3, 2009, Curitiba. Anais... Curitiba: EMBAP, 2009. 1-15.

MENDES, Sólon de Albuquerque. Análise de procedimentos imitativos na obra Electric counterpoint de Steve Reich. SIMPÓSIO ACADÊMICO DE VIOLÃO DA EMBAP, II 2008, Curitiba. Anais... Curitiba: EMBAP, 2008. 109-123.

MENDES, Sólon de Albuquerque. Experimentos composicionais para grupo de violóes. SIMPÓSIO ACADÊMICO DE VIOLÃO DA EMBAP, VI, 2012, Curitiba. Anais... Curitiba: EMBAP, 2012. 1-13.

MENDONÇA, Maurício; MEIRINHOS, Eduardo. Otimizando a performance violonística: considerações sobre práticas mentais entre violonistas. SIMPÓSIO ACADÊMICO DE VIOLÃO DA EMBAP, VIII, 2015, Curitiba. Anais... Curitiba: EMBAP, 2015. 222-229.

MODESTO, Jorge Augusto Peculas. Violão na educação básica: através do ensino coletivo, da rítmica dalcroziana e tablatura rítmica. SIMPÓSIO ACADÊMICO DE VIOLÃO DA EMBAP, VII, 2015, Curitiba. Anais... Curitiba: EMBAP, 2015. 1-13.

MORAES, Luís Felipe Vargas Magdaleno de. The Guitar Chord - an analysis of Alberto Ginastera use of the guitar as a compositional source on Sonata op. 47 for guitar. SIMPÓSIO ACADÊMICO DE VIOLÃO DA EMBAP, VI, 2012, Curitiba. Anais... Curitiba: EMBAP, 2012. 1-17.

MORAIS, Claryssa de Pádua; SCARDUELLI, Fabio. Aplicação pedagógica dos Nuevos estúdios sencillos na obra La ciudad de las columnas, de Leo Brouwer. CONGRESSO DA ASSOCIAÇÃO BRASILEIRA DE PERFORMANCE MUSICAL, IV, 2016, Campinas. Anais... Campinas: ABRAPEM, 2016. 77-86.

NASCIMENTO, Ismael Lima do. O idiomatismo na obra para violão solo de Sebastião Tapajós. SIMPÓSIO ACADÊMICO DE VIOLÃO DA EMBAP, VIII, 2015, Curitiba. Anais... Curitiba: EMBAP, 2015. 131-141.

NUNES, Emanuel de Carvalho; LOPES, Jardel de Castro. Um olhar sobre a história da atividade violonística em Teresina. SIMPÓSIO ACADÊMICO DE VIOLÃO DA EMBAP, VIII, 2015, Curitiba. Anais... Curitiba: EMBAP, 2015. 89-98.

OLIVÁREZ, Rodrigo; MATTURRO, Marcos. Malambo de Salvador Amato: técnicas instrumentais da música folclórica argentina em um arranjo para contrabaixo e violão. SIMPÓSIO ACADÊMICO DE VIOLÃO DA EMBAP, VIII, 2015, Curitiba. Anais... Curitiba: EMBAP, 


\section{278-287.}

ORELLANA, Adriano Alexandre Rivas. Digitação violonística - uma análise crítica e musical das transcriçôes de Andrés Segovia e Frank Koonce da Fuga BWV 998 de J. S. Bach. SIMPÓSIO ACADÊMICO DE VIOLÃO DA EMBAP, II, 2008, Curitiba. Anais... Curitiba: EMBAP, 2008. 304-320.

OTUTUMI, Cristiane H. Vital. Considerações iniciais sobre leitura à primeira vista, memorização e a disciplina Percepção Musical. SIMPÓSIO ACADÊMICO DE VIOLÃO DA EMBAP, V, 2011, Curitiba. Anais... Curitiba: EMBAP, 2011. 1-18.

PEREIRA, Breno Raphael de Andrade. Nova transformação de Noite de lua de Dilermando Reis para violão solo fundido a parte dos dois violóes com base na gravação original. SIMPÓSIO ACADÊMICO DE VIOLÃO DA EMBAP, IX, 2017, Curitiba. Anais... Curitiba: EMBAP, 2017. 1-15.

PEREIRA, Marcelo Fernandes. A relação entre Camargo Guanieri e os violonistas para os quais escreveu obras vista a partir de sua correspondência. SIMPÓSIO ACADÊMICO DE VIOLÃO DA EMBAP, VII, 2013, Curitiba. Anais... Curitiba: EMBAP, 2013. 172-180.

PEREIRA, Rodrigo Mateus; BERGMANN FILHO, Juarez. A luteria da guitarra barroca: notas sobre suas especificidades e construção. SIMPÓSIO ACADÊMICO DE VIOLÃO DA EMBAP, VI, 2012, Curitiba. Anais... Curitiba: EMBAP, 2012. 1-15.

PINHEIRO, Helder Tomas. Ciclo nordestino I: um estudo sobre a recriação de Marlos Nobre para duo de violões. SIMPÓSIO ACADÊMICO DE VIOLÃO DA EMBAP, VII, 2013, Curitiba. Anais... Curitiba: EMBAP, 2013. 1-11.

PINHEIRO, Helder Tomas; BIAGGI, Emerson Luiz de. Duo de violóes: reflexóes sobre poética interpretativa, repertório e digitação. CONGRESSO DA ASSOCIAÇÃO BRASILEIRA DE PERFORMANCE MUSICAL, IV, 2016, Campinas. Anais... Campinas: ABRAPEM, 2016. 149156.

PIRES, Leonardo Salgado. Estratégias de estudo para violão: levantamento primário no Portal de Periódicas da CAPES de pesquisas de Pós-Graduação realizadas no Brasil de 1987 a 2012. SIMPÓSIO ACADÊMICO DE VIOLÃO DA EMBAP, VI, 2012, Curitiba. Anais... Curitiba: EMBAP, 2012. 1-10.

PIRES, Nair; DALBEN, Ângela I. L. F. Música nas escolas de educação básica: a produção acadêmica dos cursos de pós-graduação stricto sensu no Brasil (1972-2011). Opus, v. 19, n. 2, 173210, 2013.

PIRES, Thomas König; CARVALHO, Any Raquel. Changes (1983) para violão de Elliott Carter: a construção de um plano de estudo a partir de um auto-relato. CONGRESSO DA ASSOCIAÇÂO BRASILEIRA DE PERFORMANCE MUSICAL, I, 2013, Porto Alegre. Anais... Porto Alegre: ABRAPEM, 2013. 1-10.

POLO, Victor. Carinhoso, de Pixiguinha: uma análise do arranjo e da performance de Lula Galvão 
ao violão solo. SIMPÓSIO ACADÊMICO DE VIOLÃO DA EMBAP, IX, 2017, Curitiba. Anais... Curitiba: EMBAP, 2017. 107-119.

POLO, Victor; THOMAZ, Rafael. O violão “audaz” de Toninho Horta: um olhar sobre suas aberturas de acordes formadas através do uso de pestanas com os dedos 2, 3 e 4. SIMPÓSIO ACADÊMICO DE VIOLÃO DA EMBAP, VIII, 2015, Curitiba. Anais... Curitiba: EMBAP, 2015. 313-324.

PUPIA, Adailton Sergio. A orquestra de violóes como formação camerística ao violonista. SIMPÓSIO ACADÊMICO DE VIOLÃO DA EMBAP, I, 2007, Curitiba. Anais... Curitiba: EMBAP, 2007. 1-5.

RAMPINELLI, Tamires Lemos; CERQUEIRA, Vladmir Agostini. Estratégias motivadoras para leitura musical à primeira vista: estudo de caso a partir do contexto da iniciação ao violão. SIMPÓSIO ACADÊMICO DE VIOLÃO DA EMBAP, IX, 2017, Curitiba. Anais... Curitiba: EMBAP, 2017. 89-99.

RODRIGUES, Esdras; BOLIS, Stephen Coffey. Ponteado de Antônio José Madureira: uma concepção interpretativa sobre a ótica da Música Armorial. SIMPÓSIO ACADÊMICO DE VIOLÃO DA EMBAP, VIII, 2015, Curitiba. Anais... Curitiba: EMBAP, 2015. 302-312.

RODRIGUES, Filipe Marllon Passos; CERQUEIRA, Vladmir Agostini. Um estudo de abordagem didática da pestana na iniciação ao violão sob a ótica da neutralização técnica e da motivação. SIMPÓSIO ACADÊMICO DE VIOLÃO DA EMBAP, VIII, 2015, Curitiba. Anais... Curitiba: EMBAP, 2015. 111-122.

ROMÃO, Paulo César Veríssimo. 1799 - o ano dos métodos para guitarra de seis ordens. SIMPÓSIO ACADÊMICO DE VIOLÃO DA EMBAP, V, 2011, Curitiba. Anais... Curitiba: EMBAP, 2011. 1-13.

ROSA, Renato Mendes. O tempo musical na obra Tetragrammaton XIII, de Roberto Victorio. SIMPÓSIO ACADÊMICO DE VIOLÃO DA EMBAP, VIII, 2015, Curitiba. Anais... Curitiba: EMBAP, 2015. 261-272.

SALVADOR, Ângelo Domingos. Métodos e técnicas de pesquisa bibliográfica. Porto Alegre: Sulina, 1981.

SANTOS, Diego Lima dos; MATOS, Robson Barreto. O violão sergipano: o idiomatismo na música para violão de Alvino Argollo. SIMPÓSIO ACADÊMICO DE VIOLÃO DA EMBAP, IX, 2017, Curitiba. Anais... Curitiba: EMBAP, 2017. 28-39.

SANTOS, Leandro Quintério dos; GLOEDEN, Edelton. Estratégias para organização da prática individual do violonista. SIMPÓSIO ACADÊMICO DE VIOLÃO DA EMBAP, VIII, 2015, Curitiba. Anais... Curitiba: EMBAP, 2015. 211-221.

SANTOS, Marcos Antônio Silva; FERNANDES, Stanley. Estudo 11 para violão de Heitor VillaLobos: uma macro análise. SIMPÓSIO ACADÊMICO DE VIOLÃO DA EMBAP, VIII, 2015, Curitiba. Anais... Curitiba: EMBAP, 2015. 289-301. 
SCARDUELLI, Fabio; FIORINI, Carlos Fernando. A obra para violão solo de Almeida Prado: um panorama histórico, estético e idiomático. SIMPÓSIO ACADÊMICO DE VIOLÃO DA EMBAP, I, 2007, Curitiba. Anais... Curitiba: EMBAP, 2007. 1-14.

SCHMIDT JUNIOR, Nicolau. O processo de digitação para violão do Prelúdio da Suite IV para alaúde BWV 1006a de Johann Sebastian Bach. SIMPÓSIO ACADÊMICO DE VIOLÃO DA EMBAP, VII, 2013, Curitiba. Anais... Curitiba: EMBAP, 2013. 189-196.

SEVERO, José Simião. O violão brasileiro popular no contexto formal: reflexões a partir do ensino de harmonia, improvisação e arranjo. CONGRESSO DA ASSOCIAÇÃO BRASILEIRA DE PERFORMANCE MUSICAL, VI, 2018, Natal. Anais... Natal: ABRAPEM, 2018. 220-225.

SILVA, Alessandro Pereira da; ZANIN, Fabiano Carlos; COSTA, Ricardo Vieira da. Isaias Sávio e o violão para as crianças. SIMPÓSIO ACADÊMICO DE VIOLÃO DA EMBAP, VIII, 2015, Curitiba. Anais... Curitiba: EMBAP, 2015. 1-12.

SILVA, Alexandre Luiz Alves da. Aplicação dos modelos teóricos de Swanwick na performance do violão erudito. SIMPÓSIO ACADÊMICO DE VIOLÃO DA EMBAP, VIII, 2015, Curitiba. Anais... Curitiba: EMBAP, 2015. 13-25.

SILVA, Camilla dos Santos. Métodos de técnica instrumental criados para violão erudito aplicados em alunos de violão popular com auxílio da Teoria da Autorregulação: acompanhamento e análise de resultados. SIMPÓSIO ACADÊMICO DE VIOLÃO DA EMBAP, VI, 2012, Curitiba. Anais... Curitiba: EMBAP, 2012. 1-10.

SILVA, Camilla dos Santos; SCARDUELLI, Fabio. Os resultados do estudo de técnica relacionada ao violão de concerto na performance do músico popular: relato de profissionais. SIMPÓSIO ACADÊMICO DE VIOLÃO DA EMBAP, VII, 2013, Curitiba. Anais... Curitiba: EMBAP, 2013. 18-25.

SILVA, Fabricio Ferreira da; LIRA, Ezequias Oliveira. Quando Leo Brouwer fez uma homenagem a Villa-Lobos. CONGRESSO DA ASSOCIAÇÃO BRASILEIRA DE PERFORMANCE MUSICAL, VI, 2018, Natal. Anais... Natal: ABRAPEM, 2018. 287-292.

SILVA, Felipe Augusto Vieira da. Uma breve análise da obra El arpa del guerrero de Leo Brouwer. SIMPÓSIO ACADÊMICO DE VIOLÃO DA EMBAP, II, 2008, Curitiba. Anais... Curitiba: EMBAP, 2008. 124-144.

SILVA, João Raone Tavares da. Estudo comparado das flutuações de andamento em quatro gravaçôes de Du schónes bächlein para violão solo de Hans Werner Henze. SIMPÓSIO ACADÊMICO DE VIOLÃO DA EMBAP, VIII, 2015, Curitiba. Anais... Curitiba: EMBAP, 2015. 167-176.

SILVA, José Igor Paulino da. Música e tecnologia: discussões das revistas da ABEM e da ANPPOM no período de 2004-2014. 2014. Monografia (Graduação, Música). Universidade do Estado do Rio Grande do Norte, Mossoró, 2014.

SILVA, Luciano César Moraes e. Sérgio Abreu - poética e herança histórica através de suas 
transcriçôes para violão: relato de uma pesquisa concluída. SIMPÓSIO ACADÊMICO DE VIOLÃO DA EMBAP, I, 2007, Curitiba. Anais... Curitiba: EMBAP, 2007. 1-17.

SILVA, Mário da. Elementos percussivos estruturais: uma abordagem em obras para violão de Edino Krieger e Arthur Kampela. SIMPÓSIO ACADÊMICO DE VIOLÃO DA EMBAP, II, 2008, Curitiba. Anais... Curitiba: EMBAP, 2008. 62-73.

SILVA, Pedro Augusto da; FEITOSA, Radegundis Aranha Tavares. A construção da performance musical no trombone: uma revisão de literatura. Claves, v. 2018, 1-20, 2018.

SILVA, Ricardo Fabiani; CERQUEIRA, Vladmir Agostini. Reflexóes sobre uma produção de arranjos didáticos vinculada ao processo de ensino: a experiência dos Trovadores de Santa Cruz de Minas. SIMPÓSIO ACADÊMICO DE VIOLÃO DA EMBAP, IX, 2017, Curitiba. Anais... Curitiba: EMBAP, 2017. 134-143.

SILVA, Samuel da. Simples e absurdo: um olhar sobre os aspectos harmônicos da linguagem composicional de Guinga. SIMPÓSIO ACADÊMICO DE VIOLÃO DA EMBAP, VI, 2012, Curitiba. Anais... Curitiba: EMBAP, 2012. 1-17.

SILVA, Vinicius Maurício Queiróz Hipólito da. A música brasileira pelas mãos de Paulo Belinati. SIMPÓSIO ACADÊMICO DE VIOLÃO DA EMBAP, VII, 2013, Curitiba. Anais... Curitiba: EMBAP, 2013. 325-336.

SIMÕES, Renan Colombo. O processo de revisão de três movimentos da Suíte Chaves, para violão solo, de Marcelo Rauta. CONGRESSO DA ASSOCIAÇÃO BRASILEIRA DE PERFORMANCE MUSICAL, IV, 2016, Campinas. Anais... Campinas: ABRAPEM, 2016. 259265.

SIMÕES, Renan Colombo; WINTER, Leonardo Loureiro. Decisões interpretativas em Lendas capixabas para violão solo de Carlos Cruz: subsídios para o estabelecimento de uma edição critica. CONGRESSO DA ASSOCIAÇÃO BRASILEIRA DE PERFORMANCE MUSICAL, I, 2013, Porto Alegre. Anais... Porto Alegre: ABRAPEM, 2013. 1-10.

SIMÕES, Renan Colombo; WOLFF, Daniel. Coordenação Bimanual ao Violão (CBV): discussão dos resultados de um experimento piloto com alunos do curso de Licenciatura em Música da Universidade do Estado do Rio Grande do Norte (UERN). CONGRESSO DA ASSOCIAÇÃO BRASILEIRA DE PERFORMANCE MUSICAL, VI, 2018, Natal. Anais... Natal: ABRAPEM, 2018.

SIMÕES, Renan Colombo. A obra para violão de Carlos Cruz: uma descrição dos manuscritos encontrados no acervo do compositor. SIMPÓSIO ACADÊMICO DE VIOLÃO DA EMBAP, VII, 2013, Curitiba. Anais... Curitiba: EMBAP, 2013. 243-249.

SIMÕES, Renan Colombo. O processo de revisão da peça Aberturinhazinha, para violão solo, de Marcelo Rauta. SIMPÓSIO ACADÊMICO DE VIOLÃO DA EMBAP, VIII, 2015, Curitiba. Anais... Curitiba: EMBAP, 2015. 251-260.

SKROCK, Everaldo. Violão preparado. SIMPÓSIO ACADÊMICO DE VIOLÃO DA EMBAP, I, 
2007, Curitiba. Anais... Curitiba: EMBAP, 2007. 1-5.

SUEIRO JUNIOR, Ederaldo; ALIPIO, Alisson. O processo de digitação e dedilhado do tema Assisa a pie d'un salice da Rossiniana op. 119 n. 01 de Mauro Giuliani. SIMPÓSIO ACADÊMICO DE VIOLÃO DA EMBAP, VII, 2013, Curitiba. Anais... Curitiba: EMBAP, 2013. 48-56.

TENÓRIO, Luciana Elisa Lozada. Interpretação da música renascentista: a tablatura como apoio para o intérprete moderno. SIMPÓSIO ACADÊMICO DE VIOLÃO DA EMBAP, I, 2007, Curitiba. Anais... Curitiba: EMBAP, 2007. 1-14.

TENÓRIO, Luciana Elisa Lozada. Sonata andina de Jaime M. Zenamon: análise do primeiro movimento. SIMPÓSIO ACADÊMICO DE VIOLÃO DA EMBAP, 3o, 2009, Curitiba. Anais... Curitiba: EMBAP, 2009. 1-16.

THOMAS, Rafael; SCARDUELLI, Fabio. Ritmos de gêneros brasileiros na escrita violonística de Marco Pereira. SIMPÓSIO ACADÊMICO DE VIOLÃO DA EMBAP, VII, 2013, Curitiba. Anais... Curitiba: EMBAP, 2013. 229-242.

THOMAZ, Rafael. O arranjo de Marco Pereira para My funny valentine: da leadsheet à peça. SIMPÕSIO ACADÊMICO DE VIOLÃO DA EMBAP, VI, 2012, Curitiba. Anais... Curitiba: EMBAP, 2012. 1-17.

THOMAZ, Rafael; SCARDUELLI, Fabio. O violão popular brasileiro: procurando possíveis definições. SIMPÓSIO ACADÊMICO DE VIOLÃO DA EMBAP, VIII, 2015, Curitiba. Anais... Curitiba: EMBAP, 2015. 240-250.

TORRES, Rita; FERREIRA-LOPES, Paulo. Guitar multiphonics: notations for a formalized approach. SIMPÓSIO ACADÊMICO DE VIOLÃO DA EMBAP, VII, 2013, Curitiba. Anais... Curitiba: EMBAP, 2013. 263-281.

VETROMILLA, Clayton. O Prelúdio no 2 para violão de Guerra-Peixe e a trilha sonora do filme $O$ diabo mora no sangue. SIMPÓSIO ACADÊMICO DE VIOLÃO DA EMBAP, II, 2008, Curitiba. Anais... Curitiba: EMBAP, 2008. 145-153.

VIDAL JR., Josemar. Radamés Gnattali - Estudo no 5 para violão solo e suas relações com a música caipira. SIMPÓSIO ACADÊMICO DE VIOLÃO DA EMBAP, II, 2008, Curitiba. Anais... Curitiba: EMBAP, 2008. 229-235.

VIDAL JR., Josemar. Cláudio Menandro: Sombra e água fresca. SIMPÓSIO ACADÊMICO DE VIOLÃO DA EMBAP, I, 2007, Curitiba. Anais... Curitiba: EMBAP, 2007. 1-8.

VIEIRA, Maria do Rocio R. I. Técnica de Alexander e o violonista: a educação somática, a Técnica de Alexander como influências do movimento organizacional, às práticas corporais na área da música. Simpósio Acadêmico de Violão da EMBAP, II, 2008, Curitiba. Anais... Curitiba: EMBAP, 2008. 271-280.

VOSGERAU, Dilmeire Sant'Anna Ramos; ROMANOWSKI, Joana Paulin. Estudos de revisão: implicaçốes conceituais e metodológicas. Revista Diálogo Educacional, v. 14, n. 41, 165-189, 2014. 
WIESE, Bartholomeu. Radamés Gnattali: o Concertino n. 2 para violão e orquestra e a aplicabilidade do dedo mínimo na técnica da mão direita. CONGRESSO DA ASSOCIAÇÃO BRASILEIRA DE PERFORMANCE MUSICAL, II, 2014, Vitória. Anais... Vitória: ABRAPEM, 2014. 442-450.

WILCZEK, Leonardo Allen. Variaçôes Brouwer: o processo criativo das Variaçôes sobre um tema de Brouwer, de Leonardo Wilczek. SIMPÓSIO ACADÊMICO DE VIOLÃO DA EMBAP, I, 2007, Curitiba. Anais... Curitiba: EMBAP, 2007. 1-17.

ZANÃO, Alex Anderson. A música de câmara como ferramenta no ensino de violão: uma revisão de literatura. SIMPÓSIO ACADÊMICO DE VIOLÃO DA EMBAP, V, 2011, Curitiba. Anais... Curitiba: EMBAP, 2011. 1-8.

\section{SOBRE OS AUTORES}

Jonathan Douglas Lopo Martins atuou como professor de iniciação musical em escolas públicas de Mossoró-RN, no programa Mais Educação, onde ministrou aulas de diversos instrumentos. Paralelo a essa atuação, graduou-se Licenciado em Música pela Universidade do Estado do Rio Grande do Norte(UERN). ORCID: https://orcid.org/0000-0003-42353296. E-mail: jonathanlopolopo22@gmail.com

Renan Colombo Simôes é professor Adjunto da Universidade do Estado do Rio Grande do Norte (UERN), onde desenvolve atividades de ensino (no curso de Licenciatura em Música), pesquisa e extensão. Como violonista, notabilizouse por receber mais de vinte premiaçôes como solista em concursos competitivos. Realiza apresentaçôes artísticas como solista e como integrante do Duo Capixaba de Violóes e do Coletivo NSLO, de performance e criação musical. É Bacharel em Música (Violão) pela Faculdade de Música do Espírito Santo, e Mestre e Doutor em Música (Práticas Interpretativas - Violáo) pela Universidade Federal do Rio Grande do Sul (UFRGS). ORCID: https://orcid.org/0000-0003-4478-2027. E-mail: renansimoes@hotmail.com 